\title{
Gli interventi della Chiesa di Roma nella provincia ecclesiastica milanese
}

\author{
Maria Pia Alberzoni
}

\section{Gli studi di Paul Kehr}

Nei „Nachträge zu den Papsturkunden Italiens“ apparsi nel 1912 Paul Kehr, oramai prossimo alla pubblicazione del VI volume dell'„Italia Pontificia“, stese un bilancio complessivo delle ricerche svolte negli archivi milanesi e lombardi, per le quali tanto era debitore a Hermann Kalbfuss. E in tale circostanza il Kehr formulò alcune preziose riflessioni, dalle quali intendo prendere le mosse nel presente contributo.

Egli, esaminando i principali risultati conseguiti sulla scorta della copiosa documentazione raccolta, non esitava ad affermare che, grazie ad essa, „Die Geschichte der Beziehungen des Erzbistums Mailand zu Rom wird in einigen Punkten nicht unwesentlich aufgeklärt "1. In particolare il suo interesse si appuntava sulle vicende del XII secolo, giacché a suo parere la completa sottomissione della Chiesa di Milano, tradizionalmente orgogliosa del proprio prestigio e della sostanziale autonomia nei confronti della Chiesa di Roma, poteva dirsi raggiunta nel corso del pontificato di Innocenzo II, allorché, nel 1135 l'arcivescovo Robaldo rinunciò alla consolidata prerogativa di accogliere il pallio a Milano, dalle mani di un legato, e si recò alla sede apostolica, dove ricevette dal pontefice l'ambito simbolo del potere arcivescovile. „In der Tat ist es seitdem mit der Autonomie des Mailänder Metropoliten ein für alle Mal zu Ende; von nun an häufen sich die Eingriffe Roms in die inneren Angelegenheiten der Mailänder Kirche“ (p. 365).

Il Kehr metteva quindi in luce l'assoluta fedeltà alla sede romana manifestata dagli arcivescovi di Milano a partire dagli anni quaranta del XII secolo, con particolare attenzione alla personalità di Galdino, cardinale, arcivescovo e,

1 Paul Fridolin Kenr: Nachträge zu den Papsturkunden Italiens, in: NGG Phil.-hist. Kl. 4 (1912), pp. 328-334, ora in: PUU in Italien, vol. 5 p. 364: „Für den Historiker und den Kirchenhistoriker bietet der neue Band nicht nur neues Material die Fülle, sondern auch reichen Stoff zu historischen Betrachtungen. Als ich die Regesten ordnete und den Band redigierte, drängten sich mir einige Beobachtungen auf, auf die ich hier kurz eingehen möchte, in dem Wunsche, daß sie gelegentlich von berufener Seite ausführlicher behandelt werden möchten“" 
durante tutto il suo episcopato, legato papale: „Welche außerordentliche Tätigkeit dieser Mann in dem großen Streit zwischen Friedrich I. und Alexander III. entfaltet hat, das finde ich in unsern Darstellungen dieser Zeit keineswegs genügend hervorgehoben (...). Es wäre wohl eines monographischen Versuches wert" (p. 365) $)^{2}$.

Così pure a suo giudizio gli strumenti decisivi per l'affermazione del primato papale nella provincia ecclesiastica facente capo a Milano, oltre al moltiplicarsi delle richieste di protezione apostolica per i numerosi monasteri presenti nella regione - che si accompagnò al diffondersi delle dedicazioni a s. Pietro -, a partire da Urbano II, furono i frequenti soggiorni dei papi nella regione e la partecipazione a sinodi nel corso dei loro viaggi oltralpe, la fitta presenza di legati papali, segnatamente nella seconda metà del XII secolo, nonché il fatto che alcuni membri del collegio cardinalizio provenivano dalla

2 La suggestione qui espressa dal Kehr sta alla base del lavoro di Gerhard Dunken: Die politische Wirksamkeit der päpstlichen Legaten in der Zeit des Kampfes zwischen Kaisertum und Papsttum in Oberitalien unter Friedrich I., Berlin 1931 (Historische Studien 209), pp. 9sg.: „In Oberitalien zeugte von dem Aufblühen der Hierarchie eine gesteigerte Religiosität, die auf die verschiedensten Momente zurückzuführen ist, darauf hatte schon Kehr aufmerksam gemacht. ... Mit dem Pontifikat Eugens III. beginnt so auch für Oberitalien durch das Auftreten der Legaten eine neue Aera, die auf kirchlichem Gebiete zur ,moralische Eroberung der Lombardei' und ganz Oberitaliens führen sollte“; alle osservazioni del Dunken si potrebbe aggiungere che fin dall'XI secolo l'azione dei legati nell'Italia settentrionale non era stata certo marginale. Per quanto riguarda l'arcivescovo Galdino manca ancora la monografia auspicata dal Kehr; studi utili, anche se parziali, sul personaggio sono quello di taglio agiografico di Enrico Cattaneo: Galdino della Sala cardinale e arcivescovo di Milano, in: Contributi dell'Istituto di Storia Medioevale, vol. 1: Raccolta di Studi in memoria di Giovanni Soranzo, Milano 1968 (Scienze storiche 10), pp. 129-165, quelli di Annamaria Ambrosioni: Le città italiane fra papato e impero dalla pace di Venezia alla pace di Costanza, in: La pace di Costanza 1183. Un difficile equilibrio di poteri fra società italiana e impero, Bologna 1984 (Studi e testi di storia medioevale 8), pp. 35-57, e Annamaria Ambrosioni: Alessandro III e la Chiesa ambrosiana, in: Miscellanea Rolando Bandinelli, papa Alessandro III. Studi raccolti da Filippo LiotTa, Siena 1986, pp. 3-41 (ora entrambe in Annamaria Ambrosioni: Milano, papato e impero in età medievale. Raccolta di studi, a cura di Maria Pia Alberzoni/Alfredo Lucioni, Milano 2003 [Bibliotheca erudita. Studi e documenti di storia e filologia 21], pp. 373-443, da dove saranno tratte le successive indicazioni), di Marco Pogliani: Il dissidio fra nobili e popolari a Milano. La controversia del 1203 fra l'arcidiacono e il primicerio maggiore, in: Ricerche storiche sulla Chiesa ambrosiana 10, Milano 1981 (Archivio ambrosiano 42), pp. 5-111 (con l'edizione di importanti fonti); un breve profilo in Klaus Ganzer: Die Entwicklung des auswärtigen Kardinalats im hohen Mittelalter. Ein Beitrag zur Geschichte des Kardinalkollegiums vom 11. bis 13. Jahrhundert, Tübingen 1963 (Bibliothek des Deutschen Historischen Instituts in Rom 26), pp. 114-118; i risultati di questi studi sono ripresi in Maria Pia Alberzoni: Nel conflitto tra papato e impero: da Galdino della Sala a Guglielmo da Rizolio (1166-1241), in: Diocesi di Milano, vol. 1, Brescia 1990 (Storia religiosa della Lombardia 9), pp. 227-231. 
regione padana e in essa risiedettero a lungo ${ }^{3}$. Anche a questo proposito il Kehr sottolineava l'assenza di approfondimenti storiografici su tali fenomeni („Daneben aber traten andere Faktoren in Wirksamkeit, an denen man bisher beinah achtlos vorbeigegangen ist, obwohl sie ganz offenbar von nicht geringerer Bedeutung gewesen sind“, p. 367) ${ }^{4}$, per giungere a formulare un importante suggerimento: „Eine genauere Zusammenstellung dieser Legaten, ihrer Sprengel, ihrer Funktionen und ihrer Akte wäre sehr erwünscht und gäbe uns ein sehr viel deutlicheres Bild von der ständigen Einwirkung, die die Päpste im 12. Jahrhundert auf die Verhältnisse der Lombardei ausgeübt haben, als wir es bisher besitzen" (p. 368). Accanto ai cardinali legati in Lombardia, il Kehr non tralasciava di richiamare l'attenzione sull'importante ruolo svolto dai suddiaconi papali pure incaricati dai pontefici di importanti compiti, per giungere alla conclusione: „Täuscht mich nicht alles, so ist im 12. Jahrhundert kein Land von päpstlichen Agenten hohen und niedern Ranges so sehr durchsetzt gewesen als gerade die Lombardei“ (p. 368).

L'ampio lavoro sulle fonti aveva dunque reso evidente al Kehr la necessità di considerare in modo correlato due strumenti di fondamentale importanza per comprendere gli interventi della Chiesa romana in Lombardia: i legati, soprattutto i cardinali, e i suddiaconi papali. Le ricerche in proposito sono altamente debitrici all'Italia Pontificia, anche se proprio in tale direzione sarebbe auspicabile una nuova valorizzazione del materiale documentario edito e inedito 5 .

3 Sui rapporti tra la Chiesa ambrosiana e quella romana nel XII secolo basti qui rinviare a Piero Zerbi: La Chiesa ambrosiana di fronte alla Chiesa romana dal 1120 al 1135, in: StM ser. $3^{a} 4$ (1963) pp. 136-216, ora in ID.: Tra Milano e Cluny. Momenti di vita e cultura ecclesiastica nel secolo XII, II edizione ampliata, Roma 1991 (Italia sacra. Studi e documenti di storia ecclesiastica 28), pp. 125-230, e ad Ambrosioni (cit. nota 2) in particolare agli studi della Parte seconda, pp. 297-572.

4 Il Kehr aggiungeva anche questa iportante notazione: „... ich meine die Tätigkeit des päpstlichen Legaten und der in der lombardischen Städten residierenden Kardinäle. Ich wage nicht von ständigen Legaten zu reden; aber viel fehlt nicht daran, daß man schon im 12. Jahrhundert von einer solchen Institution in der Lombardei sprechen könnte"; sulle caratteristiche dei legati residenti è di recente tornato Ludwig FalKenstein: Wilhelm von Champagne, Elekt von Chartres (1164-1168), Erzbischof von Sens (1168/69-1176), Erzbischof von Reims (1176-1202), Legat des apostolischen Stuhles, im Spiegel päpstlicher Schreiben und Privilegien, in: ZRGKanAbt 89 (2003) pp. $107-$ 284; una parte dello studio è stata pubblicata anche in francese: ID.: Guillaume aux Blanches Mains: archevêque de Reims et légat du Siège Apostolique (1176-1202), in: RHEF 91 (2005) pp. 5-25.

5 Esemplare in proposito la documentazione relativa al suddiacono papale Alexius in Papsturkunden in Frankreich N. F. 8: Paris I, ed. Dietrich Lohrmann, Göttingen 1989, pp. $62-64$ e i nn. 57-76, 85, 97, 98, 100-103, 148. L'ottima ricerca di Stefan Weiss: Die Urkunden der päpstlichen Legaten von Leo IX. bis Coelestin III. (1049-1198), Köln/Weimar/Wien 1995 (Beihefte zu den RI 13), consente di ricostruire l'attività di 


\section{La storiografia}

Nei cento anni che oramai ci separano dalle ricerche del Kehr, mentre importanti studi hanno indagato le relazioni del papato riformatore con le diverse regioni della christianitas, permane relativamente scarso il numero di contributi attenti alle modalità secondo le quali tali relazioni si attuarono: in tal senso è esemplare per il periodo altomedievale il volume di Jochen Johrendt ${ }^{6}$. È stato inoltre chiarito in modo sostanziale il ruolo svolto da movimenti e personalità di rilievo nell'orientare i rapporti tra la Chiesa romana e quella ambrosiana - basti per tutti ricordare gli studi sulla Pataria o sui viaggi di s. Bernardo ${ }^{7}$. Così pure non mancano ricerche relative agli interventi del papa nel quadro dello scontro tra regnum e sacerdotium, per orientare dal punto di vista ecclesiale e, quindi, politico, le scelte di una o più città, per le quali rinvio alla recente panoramica tratteggiata da Claudia Zey ${ }^{8}$.

alcuni suddiaconi papali, ma solo in quanto incaricati della legazione; ID.: Legatenurkunde und Papsturkunde, in: Hundert Jahre Papsturkundenforschung. Bilanz Methoden - Perspektiven. Akten eines Kolloquiums zum hundertjährigen Bestehen der Regesta Pontificum Romanorum vom 9.-11. Oktober 1996 in Göttingen, hg. v. DEms., Göttingen 2003 (AAG, phil-hist. Kl. 3. Folge 261), pp. 335-350 (p. 336-337).

6 Jochen Johrendt: Papsttum und Landeskirchen im Spiegel der päpstlichen Urkunden (896-1046), Hannover 2004 (MGH Studien und Texte 33), dove, sulla scorta della documentazione edita dallo Zimmermann, sono messi; in luce i diversi rapporti instauratisi tra il centro e la periferia, vale a dire i regni derivati dal dissolvimento dell'impero carolingio, Francia, Germania, Italia e ,Catalogna'; si veda, inoltre, Jochen Johrendt: La protezione apostolica alla luce dei documenti pontifici (896-1046), in: BISI 107 (2005) pp. 135-168.

7 Sull'azione di s. Bernardo in favore della ricomposizione dello scisma papale: Piero Zerbi: I rapporti di s. Bernardo di Chiaravalle con i vescovi e le diocesi d'Italia, in: Vescovi e diocesi in Italia nel Medioevo (sec. IX-XIII). Atti del II convegno di Storia della Chiesa in Italia (Roma, 5-9 settembre 1961), Padova 1964 (Italia sacra. Studi e documenti di storia ecclesiastica 5), pp. 219-313, ora in: Pietro Zerbi: Tra Milano e Cluny (cit. nota 3) pp. 3-109, nonché i contributi negli atti di convegni: Bernardo cistercense, Spoleto 1990 (Atti dei Convegni dell'Accademia Tudertina e del Centro di studi sulla spiritualità medievale 26) e San Bernardo e l'Italia, a cura di Pietro Zerbi, Milano 1993 (Bibliotheca erudita. Studi e documenti di storia e filologia 8).

8 Nell'impossibilità di richiamare la ricchissima bibliografia sull'argomento, mi limito a rinviare al recente e aggiornato saggio di Claudia ZEY: Im Zentrum des Streits. Mailand und die oberitalienischen Kommunen zwischen regnum und sacerdotium, in: Vom Umbruch zur Erneuerung? Das 11. und beginnende 12. Jahrhundert - Positionen der Forschung, a cura di Jörg Jarnut/Matthias Wemhoff, München 2006, pp. 595-611. Si veda ora anche il puntuale inquadramento proposto da Jochen JohrendT/Harald Müller: Zentrum und Peripherie. Prozesse des Austausches, der Durchdringung und der Zentralisierung der lateinischen Kirche im Hochmittelalter, in: Römisches Zentrum und kirchliche Peripherie. Das universale Papsttum als Bezugspunkt der Kirchen von den Reformpäpsten bis zur Innozenz III, a cura di Jochen JohrendT/Harald MüLLER, Berlin/ New York 2008 (Neue AAG 2), pp. 1-16. 
È solo il caso, poi, di accennare agli studi di Cinzio Violante sulla Pataria, a quelli di Pietro Zerbi e di Annamaria Ambrosioni, volti a indagare specificamente le relazioni tra Milano e il papato nel XII secolo, ai quali è possibile aggiungere le più recenti ricerche di Alfredo Lucioni e le considerazioni di Nicolangelo D'Acunto (per limitarmi all'ambito strettamente milanese) ${ }^{9}$. Fondamentali rimangono i contributi di Hagen Keller e della sua Scuola, che hanno consentito di meglio inquadrare il contesto sociale entro il quale si definirono scelte rilevanti nelle relazioni tra il papato e la Lombardia ${ }^{10}$.

Sull'altro versante disponiamo di studi volti a indagare importanti settori del governo della Chiesa, basti pensare ai volumi di Ina Friedländer e di Gerhard Dunken sulle legazioni papali in Lombardia nella seconda metà del XII secolo ${ }^{11}$, fino al più recente volume di Stefan Weiß, dove grazie all'esame della documentazione dei legati papali tra 1049 e 1198 si apportano anche importanti precisazioni in merito alla natura delle loro missioni, molte delle quali svolte nell'Italia padana ${ }^{12}$. Sono inoltre da ricordare diversi lavori dedicati alla ricostruzione delle carriere e dei compiti di governo svolti dai cardinali, nonché al funzionamento della curia papale, come è possibile evincere dalla ricca bibliografia ricordata da Werner Maleczek nella sua ampia e dettagliata ricerca sulla composizione e sui compiti del collegio cardinalizio tra XI e XIII secolo ${ }^{13}$.

9 Cinzio Violante: La Pataria milanese e la riforma ecclesiastica, vol. 1: Le premesse (1045-1057), Roma 1955 (Studi storici 11-13); si veda anche la valida messa a punto di Alfredo Lucioni: L'età della Pataria, in: Diocesi di Milano (cit. nota 2) pp. 167-226. Oltre agli studi ricordati sopra, alla nota 3, si veda anche ID.: L'arcivescovo Anselmo IV da Bovisio e la società milanese alla fine dell'XI secolo, in: Deus non voluit. I Lombardi alla prima crociata $(1100-1101)$. Dal mito alla ricostruzione della realtà, a cura di Giancarlo Andenna/Renata Salvarani, Milano 2003, pp. 31-217; Nicolangelo D'Acunto: Chiesa romana e chiese della Lombardia: prove ed esperimenti di centralizzazione nei secoli XI e XII, in: Johrendt/Müller: Zentrum (cit. nota 8) pp. $207-233$.

10 Hagen KeLLER: Adelsherrschaft und städtische Gesellschaft in Oberitalien (9.-12. Jahrhundert), Tübingen 1979 (Bibliothek des Deutschen Historischen Instituts in Rom 52); si veda anche la traduzione italiana: iD.: Signori e vassalli dell'Italia delle città (secoli IX-XII), Torino 1995, soprattutto per l'ampia introduzione storiografica, con importanti aggiornamenti sullo sviluppo degli studi.

11 Ina Friedlaender: Die päpstlichen Legaten in Deutschland und Italien am Ende des XII. Jahrhunderts (1181-1198), Berlin 1928 (Historische Studien 117); Dunken (cit. nota 2).

12 WeIss (cit. nota 5) pp. 339sg.

13 Werner Maleczek: Papst und Kardinalskolleg von 1191 bis 1216. Die Kardinäle unter Coelestin III. und Innocenz III., Wien 1984 (Publikationen des Historisches Instituts beim Österreichischen Kulturinstitut in Rom 1/6), pp. 207-240 e 297-350; Maleczek ha inoltre specificamente considerato il ruolo svolto dai legati papali soprattutto nel tardo medioevo: ID.: Die päpstlichen Legaten im 14. und 15. Jahrhundert, in: 
Tale quadro storiografico consente ancor più di sottolineare l'importanza dell'impresa legata al nome di Paul Kehr: l'Italia Pontificia costituisce infatti il punto di riferimento imprescindibile per tutti i lavori qui ricordati, giacché, con la segnalazione non solo dei documenti papali, ma anche di quelli dei legati, ha offerto agli studiosi uno strumento prezioso e uno stimolo alle ricerche.

D'altra parte, l'esame degli interventi messi in atto dalla sede apostolica per raggiungere quella che sempre il Kehr definì „die moralische Eroberung der

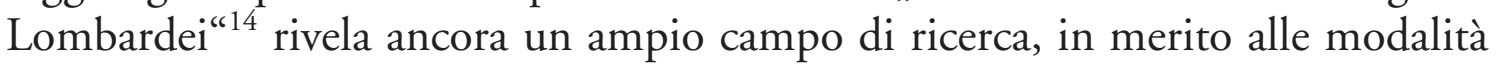
di intervento e, soprattutto, agli strumenti dei quali il papato si servì. Se infatti nell'XI secolo furono soprattutto i legati papali - la maggior parte dei quali era costituita dai vescovi legati residenti, o stabili - a rappresentare e a introdurre in sede locale le direttive della sede apostolica, nel corso del XII secolo si assistette a un affinarsi della strumentazione disponibile, da Alessandro III individuata soprattutto nei cardinali legati, nonché all'emergere di alcune interessanti sperimentazioni ${ }^{15}$.

Precisamente su questi strumenti „nuovi“, ai quali già accennava il Kehr, intendo rivolgere l'attenzione, soprattutto a partire dal pontificato di Eugenio $\mathrm{III}^{16}$. Preciso fin d'ora che non è certo possibile in questa sede procedere a un esame completo delle carriere e dell'attività degli ecclesiastici a diverso titolo coinvolti nella realizzazione delle direttive romane entro la vasta provincia ecclesiastica facente capo a Milano, che nel XII secolo comprendeva gran parte dell'Italia settentrionale e che, anche dopo la sottrazione della sede genovese (1133), si estendeva pur sempre all'attuale Piemonte e alla Lombardia, ad

Gesandtschafts- und Botenwesen im spätmittelalterlichen Europa, hg. von Rainer C. Schwinges/Klaus Wriedt, Ostfildern 2003 (VuF 60), pp. 33-86; si veda, inoltre, dello stesso autore, l'intervento nel corso del presente Convegno.

14 KeHr (cit. nota 1) p. 367.

15 Per l'azione dei cardinali sullo scorcio dell'XI secolo mi limito a rinviare ad Arimanno da Gavardo, sul quale Ganzer (cit. nota 2) pp. 40-43 e Lucioni (cit. nota 2) pp. 134139; mi valgo, inoltre, delle osservazioni di Marcel PACAUt: I legati di Alessandro III (1159-1181), in: RHE 50 (1955) pp. 821-838 e di Claudia ZeY: Die Augen des Papstes. Zu Eigenschaften und Vollmachten päpstlicher Ligaten, in: JoHrendT/ MüLLER: Zentrum (cit. nota 8) pp. 77-108; EAD.: Handlungsspielräume - Handlungsinitiativen. Aspekte der päpstlichen Legatenpolitik im 12. Jahrhundert, in: Zentrum und Netzwerk, Kirchliche Kommunikationen und Raumstrukturen im Mittelalter, a cura di Gisela Drossвach/Hans-Joachim Sснмidt, Berlin 2008 (Scrinium Friburgense 22), pp. 63-92.

16 KeHR (cit. nota 1) pp. 368sg.: „Dabei ist zugleich zu beachten, daß viele dieser Kardinäle selbst Lombarden waren und Pfründe in den dortigen Kirchen besaßen, z.T. sogar dauernd dort residierten. ... Auch den mit lombardischen Kirchenpfründen bedachten Subdiakonen des apostolischen Stuhles wäre in diesem Zusammenhange nachzugehen“. 
esclusione delle diocesi di Pavia, direttamente soggetta alla Chiesa romana, di Como, legata ad Aquileia, e di Mantova, dipendente da Grado ${ }^{17}$.

\section{Le tappe della sperimentazione}

\subsection{La presenza dei pontefici nella regione}

Come già segnalava il Kehr, i viaggi dei pontefici attraverso la regione padana diedero un contributo rilevante nel processo che condusse all'ampliamento delle prerogative papali in sede locale ${ }^{18}$. Se certo una svolta significativa si ebbe con i viaggi di Leone IX, che nel 1050 transitò nella regione e nel settembre presiedette un sinodo a Vercelli ${ }^{19}$, un importante snodo nelle relazioni tra le Chiese dell'Italia padana e il papato è da individuarsi nel viaggio e nella lunga permanenza di Urbano II nel 1095, allorché prese parte al cosiddetto concilio di Piacenza ${ }^{20}$. Nel secolo successivo, poi, soggiornarono in Lombardia Pasquale II nel 1106 e ancora nel gennaio del 1107, di ritorno rispettivamente dai regni di Francia e di Borgogna ${ }^{21}$. Callisto II attraversò la regione padana nella primavera

17 Valido punto di riferimento per uno sguardo d'insieme sono i volumi della Storia religiosa della Lombardia e del Veneto, accanto ai quali si possono segnalare, per l'attuale Piemonte, Storia della Chiesa di Ivrea dalle origini al XV secolo, a cura di Giorgio Cracco, con la collaborazione di Andrea Piazza, Roma 1998 (Chiese d'Italia 1), il recente volume Diocesi di Novara (Brescia 2007) e, per Genova, Valeria Polonio: Tra universalismo e localismo: costruzione di un sistema (569-1321), in: Il cammino della Chiesa genovese dalle origini ai nostri giorni, a cura di Dino Puncuh, Genova 1999, pp. $77-210$.

18 KeHR (cit. nota 1) p. 367.

19 Julius von Pflugk-Harttung: Acta pontificum Romanorum inedita, vol. 2, Stuttgart 1884 (Graz 1958), p. 75 n. 109: cum consilio coepiscoporum nostrorum in synodo, quod habuimus Vercellis, decrevimus; IP 6/2 p. 122 n. 2 (Torino, S. Michele alla Chiusa). Il percorso del papa è ricostruibile sulla base di JL vol. 1 p. 538-540; una attenta analisi dei motivi che ispirarono i viaggi papali, con una puntuale messa a punto sulla permanenza dei pontifici nell'Italia meridionale in Jochen Johrendt: Die Reise der frühen Reformpäpste - Ihre Ursachen und Funktionen, in: RQ 96 (2001) pp. 57-94.

20 IP 6/2 pp. 124sg. n. 11 (datum Placentiae); il percorso seguito da Urbano II durante la sua permanenza nell'Italia settentrionale tra il febbraio e il luglio del 1095, quindi di ritorno dal regno di Francia nel settembre-ottobre 1096, si può ricostruire sulla base di JL vol. 1 pp. 676-680 e 690; Giorgio PICAsso: Il Concilio di Piacenza nella tradizione canonistica, in: Il Concilio di Piacenza e le Crociate, Piacenza 1996, pp. 109-119.

21 La sosta di Pasquale II a Casale Monferrato è attestata in «Fragmentum martyrologii ecclesiae Beati Evasii Casalensis», in: Monumenta historiae patriae, Scriptores 3, Augustae Taurinorum 1848, col. 446; si vedano le indicazioni in IP 6/2 p. 42 n. * ${ }^{*}$ : il Kehr segnala però la notizia offerta dal Chronicon di Ekkehardus, secondo la quale Pasquale II avrebbe trascorso il Natale 1106 a Cluny. L'itinerario del viaggio del papa è ricostruibile sulla base di JL vol. 1 pp.726-728; si veda inoltre Glauco Maria 
del 1120 diretto dalla Borgogna verso Roma ${ }^{22}$; Innocenzo II, anch'egli sulla via che dal regno di Francia lo conduceva a Roma tra l'aprile e l'agosto del $1132 \mathrm{fu}$ ad Asti, Novara, Mortara, Pavia, Piacenza, Cremona e Brescia ${ }^{23}$; Eugenio III transitò in Lombardia nel marzo del 1147 e, di ritorno dal concilio di Reims, nel mese di giugno del 1148 fu a Vercelli, dove, alla presenza di quattordici cardinali, di numerosi prelati e dell'abate Bernardo di Clairvaux, consacrò la cattedrale di S. Maria; quindi si diresse a Cremona per tenervi un sinodo con i vescovi lombardi ${ }^{24}$, attraversando diverse città della regione ${ }^{25}$.

A questi soggiorni in itinere sono da aggiungere la permanenza di Alessandro III a Venezia, dal 9 maggio fino alla metà di ottobre $1177^{26}$, i circa tre anni trascorsi dalla curia papale a Verona sullo scorcio del pontificato di Lucio III, precisamente dall'estate del 1184 fino alla sua morte avvenuta il 25 novembre $1185^{27}$, e per tutto quello di Urbano III $(1185-1187)^{28}$ : si trattò di un periodo contraddistinto da relazioni assai strette tra il papato e le Chiese dell'Italia padana, un motivo ancor più evidente allorché si consideri l'origine milanese di

Cantarella: Pasquale II, in: Enciclopedia dei papi, vol. 2, Roma 2000, pp. 228-236, soprattutto $229-230$.

22 Giovanni Miccoli: Callisto II, in: Enciclopedia dei papi (cit. nota 21) pp. 248-254, alle pp. 251-252 un breve cenno dell'incontro avvenuto a Tortona tra il papa e il cronista milanese Landolfo di S. Paolo; IP 6/2 p. 43 n. 4, l'edizione in: Ferdinando Gaвотто/Umberto Fisso: Le carte dello Archivio capitolare di Casale Monferrato fino al 1313, vol. 1, Pinerolo 1907 (Biblioteca della Società Storica Subalpina 40), pp. 14sg. n. X (Piacenza, 1120 aprile 23: si tratta della conferma da parte di Callisto II dei beni e dei privilegi della chiesa di Casale Sant'Evasio); l'itinerario del papa si può ricostruire grazie a JL vol. 1 pp. 794sg.

23 IP 6/2 p. 23 nn. 8-10: per l'itinerario del papa si veda JL vol. 1 pp. 856-858; qualche cenno alla sosta piacentina in Tommaso Di CARpegna Falconieri: Innocenzo II, in: Enciclopedia dei papi (cit. nota 21) pp. 261-268, soprattutto pp. 264-265.

24 Litinerario del pontefice verso il regno di Francia come pure le tappe del suo ritorno sono evincibili rispettivamente da JL vol. 2 p. 39 e pp. 58-59; si veda anche Harald ZimmermanN: Eugenio III, in: Enciclopedia dei papi (cit. nota 21) pp. 279-285 (per il viaggio pp. 280 -282). Sulla consacrazione della basilica di S. Maria (1148 giugno 17) vedi IP 6/2 p. 23 n. 9; su tale circostanza Laura Minghettr Rondoni: San Bernardo alla consacrazione della cattedrale di S. Maria di Vercelli, in: San Bernardo e l'Italia (cit. nota 7) pp. $141-147$.

25 Si veda, ad esempio, PUU in Italien, vol. 3 pp. $120-122$ n. 6 (1148 luglio 7): Eugenio III, da Cremona, conferma i possessi dei canonici di Novara; per l'itinerario vedi JL vol. 2 p. 58 sg.

26 Paolo Brezzi/Andrea Piazza: Alessandro III, in: Enciclopedia dei papi (cit. nota 21) pp. 291-302.

27 Grado Giovanni Merlo: Lucio III, in: Enciclopedia dei papi (cit. nota 21) pp. $308-$ 311; gli spostamenti verso Verona sono ricostruibili sulla base di JL vol. 2 pp. 465sg.: Lucio III lasciò Sora diretto ad Ancona alla fine di maggio 1184; il 22 luglio era a Verona, dove rimase fino alla morte.

28 Ganzer (cit. nota 2) pp. 134-136; Paolo Grillo: Urbano III, in: Enciclopedia dei papi (cit. nota 21) pp. 311-314. 
Urbano III. Durante questo triennio l'esercizio di una giurisdizione diretta del vescovo di Roma sulle Chiese della regione padana assunse tratti meglio definiti: basti qui ancora accennare al pur breve pontificato di Urbano III (25 novembre 1185-20 ottobre 1187), che anche come pontefice continuò a intrattenere strette relazioni (soprattutto tramite la concessione di privilegi e la soluzione di cause giudiziarie) con numerose istituzioni ecclesiastiche dell'Italia settentrionale, dalle quali sperava di ricevere il necessario appoggio per sottrarsi all'isolamento in cui Federico I lo costringeva ${ }^{29}$.

\subsection{I cardinali originari della regione padana}

Accanto alla personale presenza dei pontefici e della curia papale è opportuno considerare quella dei cardinali provenienti dalle Chiese lombarde, che, grazie alle accurate ricerche condotte nel corso dello scorso secolo e messe a frutto nell'opera di Werner Maleczek, siamo in grado di individuare agilmente. Costoro, infatti, non furono solo attivi al fianco del papa, ma a loro fu spesso affidato il compito della legazione nelle rispettive terre d'origine, dove talora si trattennero per soggiorni prolungati ${ }^{30}$. Va inoltre accennato che sovente la presenza di cardinali legati nell'Italia settentrionale è da porre in relazione al transito verso le terre d'oltralpe meta della legazione, una evenienza spesso sfruttata per visitare $\mathrm{i}$ centri a loro più noti, per risiedervi anche solo temporaneamente e per svolgervi importanti uffici.

Fin dall'XI secolo la scelta dei pontefici fu certo suggerita dalla sempre più sentita necessità di garantire un raccordo organico tra la regione e la sede apostolica, sia al fine di affermare l'autorità del vescovo di Roma nei confronti dell'episcopato dell'Italia settentrionale, sia - e questo soprattutto a partire dal pontificato di Alessandro III - per garantire il necessario raccordo politico con i più forti alleati del pontefice nello scontro con Federico I e gli antipapi a lui fedeli ${ }^{31}$.

29 Annamaria Ambrosioni: Monasteri e canoniche nella politica di Urbano III. Prime ricerche per la ,Lombardia', in: Istituzioni monastiche e istituzioni canonicali in Occidente (1123-1215). Atti della settima Settimana internazionale di studio (Mendola 28 agosto-3 settembre 1977), Milano 1980, pp. 601-631, ora in Ambrosioni (cit. nota 2) pp. 337-372.

30 Maleczzek Papst (cit. nota 13) pp. 251sg.

31 Pacaut (cit. nota 15) pp. 824-828; Ovidio Capitani: Alessandro III, lo scisma e le diocesi dell'Italia settentrionale, in: Popolo e Stato nell'età di Federico I Barbarossa. Alessandria e la Lega lombarda. Relazioni e comunicazioni al XXXIII Congresso storico subalpino per la celebrazione dell'VIII centenario della fondazione di Alessandria (Alessandria, 6-9 ottobre 1968), Torino 1970, pp. 221-238; Ambrosioni (cit. nota 2) pp. $376-390$ e $428-434$. 
Consideriamo brevemente le nomine: nel 1133 fu creato cardinale il piacentino Azzo (1133-1139) ${ }^{32}$, seguito nel decennio successivo ancora dal concittadino Ribaldo $(1143-1156)^{33}$, dai milanesi Goizone $(1140-1144)^{34}$ e Guido da Somma $(1143-1151)^{35}$, dal novarese Ugo $(1144-1150)^{36}$, dal bolognese Guarino (1144-post 1154) ${ }^{37}$ e da Guido da Crema (1145), passato tra i più decisi sostenitori di Federico I, quindi dal 1164 antipapa con il nome di Pasquale III $(1164-1168)^{38}$. Nel 1151 fu la volta di Ildebrando Crassus, forse appartenente alla canonica regolare di S. Maria de Reno di Bologna (1152$1178)^{39}$, di Oddo da Brescia $(1152-1174)^{40}$, poi di Ardizzone da Rivoltella

32 Maleczex Papst (cit. nota 13) p. 242, fissa le date del cardinalato di Azzo tra 1134 e 1139, anno della morte; in realtà Azzo è definito già nel 1133 cardinale diacono della Chiesa romana, nonché preposito della canonica di S. Antonino (vedi anche PUU in Italien, vol. 3 pp. $245-247 \mathrm{nn} .6$ e 7), mentre la promozione al titolo presbiterale di S. Anastasia, ad opera di Innocenzo II, risale al 1134; anche WeIss (cit. nota 5) p. 132, ignora la precedente carriera; oltre a Gian Paolo Bulla: Amministrazione, patrimonio e potere della basilica di S. Antonino nella Piacenza del XII secolo, in: Bollettino storico piacentino 92 (1997) p. 42, si veda ora Ivo Musajo Somma: Il capitolo della cattedrale di Piacenza nel XII secolo (1155-1199), tesi di Dottorato di ricerca in Storia medievale (ciclo XV), Università Cattolica di Milano a. a. 2002/2003, pp. 61-67.

33 Maleczer Papst (cit. nota 13) p. 242: Ribaldo, canonico della cattedrale piacentina, fu creato cardinale prete di S. Anastasia (1146-1156); Musajo Somma (cit. nota 32) pp. 66 e 139.

34 Maleczer Papst (cit. nota 13) p. 242: cardinale prete di S. Cecilia; su di lui Weiss (cit. nota 5) p. 147.

35 Maleczek Papst (cit. nota 13) p. 242: cardinale prete di S. Lorenzo in Damaso nel 1143, nel 1149 promosso alla sede episcopale di Ostia († 1151); si veda anche WeIss (cit. nota 5) p. 163.

36 Maleczer Papst (cit. nota 13) p. 242: cardinale prete di S. Lorenzo in Lucina; Weiss (cit. nota 5) p. 159.

37 Maleczer Papst (cit. nota 13) p. 242: cardinale vescovo di Preneste; Roger Aubert: Guarinus, in: DHGE 22, Paris 1988, coll. 559-560.

38 Maleczer Papst (cit. nota 13) p. 242: nel 1145 creato cardinale diacono di S. Maria in Portico e nel 1158 promosso al titolo presbiterale di S. Maria in Trastevere; WeIss (cit. nota 5) p. 161.

39 Johannes Matthias Brixius: Die Mitglieder des Kardinalkollegiums von 1130-1181, Diss. Berlin 1912, p. 55 n. 12 e p. 109 nota 128; Barbara Zenker: Die Mitglieder des Kardinalkollegiums von 1130-1159, Diss. Würzburg 1964, pp. 107-109; DunkeN (cit. nota 2) pp. 19-20 (Ildebrando dal 1148 fu rettore o amministratore vescovile della chiesa di S. Giminiano di Modena), 83-87, 103-107, 117-120; GANZER (cit. nota 2) pp. 100-102; Roger Auber t: Hildebrand, in: DHGE 24 (1993) coll. 485-488; Weiss (cit. nota 5) pp. 207-212: nel 1152 sottoscrive come sancte Romane ecclesie diaconus cardinalis; dal 30 gennaio 1153 cardinale diacono di S. Eustachio, dal 1154 Mutinensis ecclesie rector et procurator, alla fine del 1156 creato cardinale prete dei SS. XII Apostoli ( $\dagger$ $1178)$.

40 Maleczer Papst (cit. nota 13) p. 242: cardinale diacono di S. Nicola in Carcere Tulliano; WeIss (cit. nota 5) pp. 212-217. 
$(1157-1186)^{41}$ e di Guglielmo da Pavia (o de Marengo) $(1158-1178)^{42}$. Alessandro III creò cardinali Manfredo di Lavagna $(1162-1178)^{43}$, Ugo da Bologna $(1166-1177)^{44}$, Galdino della Sala $(1165-1167)$, poi arcivescovo di Milano $^{45}$, Lombardo da Piacenza (1171), poi arcivescovo di Benevento ${ }^{46}$, Petro

41 Paolo Lamma: Ardizzone da Rivoltella, in: DBI 4 (1962) pp. 41-42; Ganzer (cit. nota 2) pp. 133sg.; Maleczen Papst (cit. nota 13) p. 242: creato nel 1157 cardinale diacono di S. Teodoro. La controversa provenienza di questo ecclesiastico (da Ottone Morena indicato come de Rivoltella) dal territorio bergamasco, bresciano o cremonese, sembra essere definitivamente risolta in favore della sua origine cremonese/bergamasca da un documento del 1176 dicembre 7, edito da Cesare Vignati: Codice diplomatico laudense, vol. 2, Milano 1885, n. 75 e, ora, da Ada Grossi: Il Liber iurium del Comune di Lodi, Roma 2004 (Pubblicazioni degli Archivi di Stato 42), nn. 94 e 96, consultabile anche in: Codice diplomatico della Lombardia medievale (www.cdlm.unipv.it/edizione/ lo/cerreto-spietro).

42 Weiss (cit. nota 5) pp. 232-239; Guglielmo da Pavia, viene definito de Marengo (forse perché originario di Bosco Marengo, località in diocesi di Tortona, destinata in seguito a essere uno dei centri su cui si articolerà la nascita di Alessandria) in un testimoniale redatto il 3 dicembre 1177, relativo a una causa circa la dipendenza dal vescovo di Novara dell'ospedale e della chiesa di S. Maria di Barzi (1177 dicembre 3), in: Oreste Scarzello/Giovanni Battista Morandi/Andrea Leone: Le carte dell'Archivio capitolare di S. Maria di Novara, Torino 1924 (Biblioteca della Società Storica Subalpina 80), pp. 38sg. n. CDXCIV: Et eo tempore (oltre 4 anni prima, presumibilmente nel 1172), pro illa discordia fuimus ante Guilielmum cardinalem, qui tunc uenerat in partes illas et nuntiauimus ei discordiam illam (...). Predictus Otto, reuersus, dixit (...); et post hoc uidi similiter discordiam inter conuersos ipsius domus et posuerunt eam sub dompno Guilielmo de Marengo, et fuit ab annis tribus infra de illa discordia que fuit sub ipso Guilielmo; questa testimonianza è finora sfuggita alla storiografia. Guglielmo era stato arcidiacono della cattedrale pavese ed era insignito del titolo di magister; nel maggio del 1158 fu creato da Adriano IV cardinale prete di S. Pietro in Vincoli e alla fine di dicembre del $1176 \mathrm{fu}$ promosso da Alessandro III cardinale vescovo di Porto ( $\dagger 18$ gennaio 1178); oltre a Fedele SAvio: Gli antichi vescovi d'Italia dalle origini al 1300 descritti per regioni. La Lombardia, 2/2: Cremona - Lodi - Mantova - Pavia, Bergamo 1932, p. 434, e a Roger Aubert: Guillaume de Pavie, in: DHGE 22 (1988) coll. 982sg., si veda ora Stephan Freund: Guglielmo da Pavia, in: DBI 61 (2003) pp. 22-25 e Maria Pia Alberzoni: Vercelli e il papato, in: Vercelli nel secolo XII. Atti del quarto Congresso storico vercellese, Vercelli 2005, pp. 101-103; EAD.: Norditalienische Pilgerhospize im 12. und 13. Jahrhundert, in: Wege zum Heil. Pilger und heilige Orte an Mosel und Rhein, a cura di Thomas Frank, Stuttgart 2009, pp. 271-290 (p. 282).

43 Maleczer Papst (cit. nota 13) p. 243: nel dicembre 1162 creato cardinale diacono di S. Giorgio in Velabro, nel 1163 cardinale prete di S. Cecilia, quindi dal 1176 al 1178 cardinale vescovo di Preneste; Weiss (cit. nota 5) p. 243; Alberzoni Vercelli (cit. nota 42) p. $103-104$.

44 Maleczer Papst (cit. nota 13) p. 242: cardinale diacono di S. Eustachio.

45 Maleczer Papst (cit. nota 13) p. 242: cardinale prete di S. Sabina (1165-1167, il Maleczek indica 1166 perché, essendo avvenuta in dicembre la sua creazione, le sottoscrizioni iniziano con l'anno successivo), quindi arcivescovo di Milano fino alla morte (1176); si vedano gli studi ricordati sopra, alla nota 2. 
da Pavia $(1173-1182)^{47}$, Raniero Parvo da Pavia $(1175-1183)^{48}$. Da Lucio III furono accolti nel collegio cardinalizio il milanese Uberto Crivelli (11821185), poi papa Urbano $\mathrm{III}^{49}$, che, a sua volta, nel 1185 creò cardinale il veronese Adelardo, dal 1188 fino alla sua morte, presumibilmente avvenuta nel 1214, vescovo della sua città ${ }^{50}$, e il piacentino Pietro Diani $(1185-1206)^{51}$; Clemente III, infine, creò cardinale il lombardo Giovanni, già vescovo di Tuscania, dal 1189 cardinale prete di S. Clemente e dal 1199 al 1210 cardinale vescovo di Albano ${ }^{52}$.

46 Maleczer Papst (cit. nota 13) p. 243: cardinale prete di S. Ciriaco (1171), poco dopo trasferito alla sede beneventana Ganzer (cit. nota 2) pp. 121-123.

47 Cardinale prete di S. Grisogono (1173-1179), quindi cardinale vescovo di Tuscolo (1179-1182): la sua biografia è ricostruita da Dietrich Lohrmann: Petrus von St. Viktor in Paris. Zur Vorgeschichte eines Legaten Alexanders III. in Frankreich, in: Deus qui mutat tempora. Menschen und Institutionen im Wandel des Mittelalters. Festschrift für Alfons Becker zu seinem 65. Geburtstag, hg. von Ernst-Dieter HeHL, Sigmaringen 1987, pp. 259-267 (che chiarisce la sua precedente carriera come arcidiacono di Pavia, quindi come abate di Saint-André di Chartres); su di lui anche Wilhelm Janssen: Die päpstlichen Legaten in Frankreich vom Schisma Anaklets II. bis zum Tode Coelestins III. (1130-1198), Köln/Graz 1961, pp. 92-108; indubbiamente, come ben chiarisce il Lohrmann, il fatto che fosse arcidiacono di Pavia non garantisce circa la sua origine lombarda, ma diversi indizi sembrano piuttosto accreditarla e a tal fine sono interessanti le osservazioni di Weiss (cit. nota 5) pp. 254-265; Maleczzex Papst (cit. nota 13) p. 244 indica invece Pietro come di origine francese; ritengo di poterlo considerare ,lombardo', sia per la provenienza a lui attribuita nelle cronache, sia per l'indubbio stretto legame con un altro esponenste del collegio cardinalizio, Guglielmo da Pavia: una chiara testinionianza in tal senso è offerta da una lettera indirizzata a Pietro da Alessandro III il 27 marzo 1178, con la quale il cardinale era incaricato di recuperare e di portare alla curia alcuni oggetti preziosi, già appartenuti a Guglielmo da Pavia e che questi aveva lasciato a Limoges (Migne PL 200 coll. 1163sg.).

48 Maleczer Papst (cit. nota 13) p. 242: Raniero nel 1175 fu creato cardinale diacono di S. Giorgio in Velabro, nel 1182-1183 fu promosso cardinale prete dei SS. Giovanni e Paolo; Weiss (cit. nota 5) p. 268.

49 Maleczek Papst (cit. nota 13) p. 243; Ganzer (cit. nota 2) pp. 134-136: creato nel 1182 cardinale prete di S. Lorenzo in Damaso, dal 1185 arcivescovo di Milano; per la sua legazione, vedi Weiss (cit. nota 5) pp. 285sg.

50 Maleczek Papst (cit. nota 13) pp. 68 e 243: creato nel 1185 cardinale prete di S. Marcello, dal 1188 al 1212 vescovo di Verona, vedi Ganzer (cit. nota 2) pp. 137-140.

51 Maleczek Papst (cit. nota 13) pp. 85sg.; id.: Diani, Pietro, in: DBI 39 (1991) pp. 648-650; ID.: Zwischen lokaler Verankerung und universalem Horizont. Das Kardinalskollegium unter Innocenz III., in: Innocenzo III. Urbs et orbis. Atti del Congresso Internazionale (Roma, 9-15 settembre 1998), a cura di Andrea SommerLECHNER, vol. 1, Roma 2003 (Nuovi Studi storici 55), pp. 102-154, qui pp. 133-134; GanZer (cit. nota 2) pp. 136sg.; Weiss (cit. nota 5) pp. 290-294.

52 MaleczeK Papst (cit. nota 13) pp. 94sg. e 243: dal 1188 vescovo di Tuscania (dal 1192 di Viterbo-Tuscania), creato cardinale prete di S. Clemente nel 1189 e nel 1199 promosso alla sede episcopale di Albano († 1210-1211). 
Si tratta dunque di una presenza ininterrotta, particolarmente nutrita a partire dalla metà del secolo, la cui importanza non va sottovalutata nell'esame delle relazioni tra la provincia ecclesiastica di Milano e la sede romana.

\subsection{I legati papali}

I più significativi interventi della sede apostolica nella regione, soprattutto negli anni dello scontro tra Federico I e Alessandro III, furono affidati ai legati papali, che nella maggioranza dei casi erano anche cardinali.

Non intendo qui proporre una panoramica completa in merito alla loro azione, giacché a tale proposito è possibile rinviare agli studi sopra ricordati, in particolare a quello di Gerhard Dunken. Mi limiterò piuttosto a formulare alcune considerazioni sull'attività dei legati a partire dall'esame della carriera di alcuni dei più attivi nella regione padana, in primo luogo di quella di Galdino della Sala, al fine di individuare sia la linea d'azione perseguita dalla sede apostolica, sia gli strumenti di cui fece uso nelle diverse circostanze.

\subsubsection{Arcivescovo e legato papale: il cardinale Galdino della Sala.}

L'ammirazione del Kehr e del Dunken per l'intensa azione svolta da Galdino si comprende facilmente anche solo grazie a un rapido sguardo ai suoi interventi più significativi, promossi per rafforzare il fronte alessandrino, anche dal punto di vista politico, quindi nell'opposizione a Federico I nell'Italia settentrionale: di fatto fu grazie all'attività dei legati che il papa ottenne l'auspicato successo non solo all'interno della Chiesa, ma anche nei confronti del sovrano ${ }^{53}$.

Il 5 settembre 1167, dopo oltre cinque anni di lontananza, Galdino, che quando nel 1162 all'avvicinarsi degli eserciti imperiali e delle città nemiche aveva abbandonato la città era arcidiacono della cattedrale, rientrava a Milano come cardinale - nel dicembre del 1165 Alessandro III lo aveva creato cardinale prete di S. Sabina -, arcivescovo e legato papale, o come „Papstvikar für Oberitalien", come il Dunken lo definì ${ }^{54}$. Non solo: con il suo rientro nella città anche la diocesi e la provincia ecclesiastica tornavano in qualche modo a esistere

53 Si tratta di un motivo giustamente enfatizzato dal Dunken (cit. nota 2) p. 94: „so ist damit unzweifelhaft der Beweis geliefert, daß in diesen Jahren dem deutschen Kaiser in den päpstlichen Legaten die bedeutendsten Politiker der Kurie entgegengetreten sind und ihm die Basis seiner oberitalienischen Machtpolitik entrissen haben", ampiamente accolto dalla successiva storiografia.

54 Ibid. pp. 80sg.: „Mailand wurde durch Galdin der Mittelpunkt der alexandrinischen Propaganda im zweiten Abschnitt des Schismas. Galdins Stellung selbst wurde nochmals erhöht durch seine Ernennung zum ,Legatus contra Imperium Aenobarbi'. Es war das eine kluge Politik Alexanders III., dem Mailänder Metropoliten durch seine Ernennung zum Legaten, d.h. zum Papstvikar für Oberitalien mit dem ständigen Sitz in Mailand.“ 
e a essere attive al fianco di Alessandro III. Notiamo in primo luogo che Galdino dopo la consacrazione episcopale non si intitolò più cardinale, ma arcivescovo e legato papale, un motivo peraltro consueto in un momento in cui la carica episcopale era considerata eminente rispetto a quella cardinalizia ${ }^{55}$. D'altra parte giustamente è stato fatto notare che il fenomeno dell',,auswärtiges Kardinalat" piuttosto che „una istituzione vera e propria“ sia „il sintomo di un nuovo stile di governo della Chiesa universale ${ }^{\text {" } 56}$, che si sviluppa a partire dal pontificato alessandrino: in tal senso l'esame delle singole carriere consente di mettere a fuoco gli snodi più significatici di tale evoluzione, di fondamentale importanza per l'affermazione sempre più netta del primato papale.

Nell'accostare con una rapida carrellata i principali interventi attuati dal legato non bisogna però dimenticare che nel periodo della sua attività anche altri legati o cardinali legati furono attivi nella regione: delle loro coeve iniziative si darà conto, ma sempre in relazione all'attività dell'arcivescovo di Milano.

Il primo campo entro cui si sviluppò l'azione di Galdino fu teso a riportare il clero della città e della diocesi all'obbedienza alessandrina: si tratta di un ambito geografico entro il quale egli avrebbe potuto far valere la sua autorità anche solo in quanto metropolita, ma certo la qualità degli interventi richiesti aveva suggerito l'opportunità di rafforzare la sua posizione con il compito di legato. Probabilmente già nel 1168, l'arcivescovo pose a capo della canonica di S. Giovanni Battista di Monza il milanese e suddiacono della Chiesa romana Oberto da Terzago ${ }^{57}$. Fin dal mese di marzo del 1168 inviò a Lodi gli abati dei monasteri cittadini di S. Ambrogio e di S. Vincenzo, che indussero il clero locale, allora fedele a Federico I e all'antipapa Pasquale III (il lombardo Guido da Crema), al completo riconoscimento di Alessandro III, alla deposizione del vescovo scismatico e all'elezione di un presule obbediente alle direttive di Galdino $^{58}$. Così pure, in questo caso grazie esclusivamente all'autorità di legato apostolico, Galdino fin dal 1167 aveva provveduto a sostituire il vescovo filoimperiale di Como con un altro favorevole ad Alessandro III; analoghi provvedimenti furono presi per altre diocesi suffraganee, quali Novara e

55 Ganzer (cit. nota 2) pp. 187-204; id.: Das roemische Kardinalkollegium, in: Le istituzioni ecclesiastiche della „societas christiana“ dei secoli XI-XII. Papato, cardinalato ed episcopato. Atti della quinta Settimana internazionale di studio (Mendola, 26-31 agosto 1971), Milano 1974, pp. 153-181, qui soprattutto pp. 179sg.: nell'uso di abbandonare o mantenere il titolo cardinalizio anche dopo la nomina a una sede vescovile il pontificato di Alessandro III costituì una sorta di spartiacque, poiché a partire dal suo pontificato prevalse l'uso di mantenere in ogni caso il titolo di sancte Romane ecclesie cardinalis, accanto a quello della sede episcopale ricoperta.

56 Carl Gerold Fürst: Intervento nella discussione della lezione di Klaus Ganzer ricordata alla nota 55, in: Le istituzioni ecclesiastiche (cit. nota 55) p. 184, e MaLeczeK Papst (cit. nota 13) pp. 251sg.

57 Ambrosioni (cit. nota 2) pp. 429sg.

58 Dunken (cit. nota 2) pp. 81sg.; Ambrosioni (cit. nota 2) pp. 431-433. 
Cremona $^{59}$. Ancora nel 1168 ebbe inizio la costruzione di Alessandria, con la costituzione della relativa diocesi, ovviamente suffraganea di Milano, eretta sottraendo alcune pievi alle vicine Pavia, Asti e Acqui, che fino ad allora si erano mostrate favorevoli a Federico I ${ }^{60}$. Proprio contro Pavia, dove il vescovo fedele ad Alessandro III era stato costretto all'esilio, Galdino rinnovò l'interdetto, decretato nel 1160 dal cardinale Giovanni di S. Maria in Portico ${ }^{61}$. Anche gli abitanti del Seprio, che nel 1158 avevano aderito a Federico I, nel marzo del 1168 giurarono di stare praeceptis Galdini archiepiscopi et conscilii Mediolani e, per rendere ancora più evidente la volontà di controllare quel territorio a nord di Milano, l'arcivescovo, contro le consuetudini locali, nominò arciprete di S. Maria del Monte a Varese il diacono della Chiesa ambrosiana Pietro da Bussero $^{62}$. Nel 1169 Galdino allontanò il vescovo scismatico di Alba e provvide alla nomina di un successore di fiducia e nell'anno successivo un'analoga sorte toccò ai vescovi di Bergamo e Vercelli; nel 1170 fu la volta della sostituzione del vescovo di Asti ${ }^{63}$. Sempre nel 1170 Galdino riuscì a insediare a Torino il milanese Milone da Cardano e a sostituire il vescovo filoimperiale di Tortona ${ }^{64}$.

59 Dunken (cit. nota 2) p. 82; Ambrosioni (cit. nota 2) p. 430.

60 Sulla fondazione di Alessandria un esauriente quadro è offerto da Geo Pistarino: Alessandria nel mondo dei Comuni, in: StM ser. $3^{\text {a }} 11$ (1970) pp. 1-101; la documentazione pontificia agli inizi della diocesi di Alessandria è in IP 6/2 pp. $201-$ 202; di grande utilità la ricostruzione di Giulio Fiaschini: La fondazione della diocesi di Alessandria ed i contrasti con i vescovi acquesi, in: Popolo e stato (cit. nota 31) pp. 496512; si veda anche ID.: Chiesa e Comune in Acqui medievale, Acqui 1969.

61 Dunken (cit. nota 2) pp. 82 sg.; SAvio (cit. nota 42) pp. 430-437; Weiss (cit. nota 5) pp. $242 \mathrm{sg}$.

62 Ambrosioni (cit. nota 2) p. 431; su Pietro da Bussero e la sua intensa opera dal punto di vista amministrativo: Juliane TREDE: Untersuchungen zum Verschriftlichungsprozeß im ländlichen Raum Oberitaliens. Die Urkunden der Pilgerkirche S. Maria di Monte Velate bei Varese aus dem 12. und 13. Jahrhundert, Frankfurt am Main 2000 (Gesellschaft, Kultur und Schrift. Mediävistische Beiträge 9), pp. 202-208; importanti precisazioni circa la data della nomina e dell'ingresso di Pietro nella nuova carica sono in Alfredo Lucioni: Cronologia degli arcipreti di S. Maria di Monte Velate per i secoli X-XVI, in: Rivista della Società storica varesina 24 (2006-2007) pp. 11-33 (soprattutto 21-22).

63 Dunken (cit. nota 2) p. 93; il Dunken aggiunge a quesi casi anche la sostituzione del vescovo di Cremona, ma secondo SAvio (cit. nota 42) pp. 86-87, il presule filofedericiano Presbitero da Medolago era stato allontanato dalla sua sede prima del 23 aprile 1167, quando risulta già presente Offredo (consacrato entro il 29 maggio 1168).

64 Dunken (cit. nota 2) p. 93; Ambrosioni (cit. nota 2) p. 432; su Milone da Cardano si veda ora anche Renato Bordone: Il movimento comunale: le istituzioni cittadine e la composizione sociale durante il XII secolo, in: Storia di Torino, vol. 1: Dalla preistoria al comune medievale, a cura di Giuseppe SERGI, Torino 1997, pp. 639-646. 
Infine, nel 1175, l'arcivescovo ottenne che venisse nominato vescovo di Alessandria il suddiacono papale Arduino ${ }^{65}$.

Gli interventi di Galdino si concentrarono dunque con singolare intensità nella zona che corrisponde a grandi linee alla parte centro-occidentale della vasta provincia ecclesiastica, della quale peraltro non facevano parte Como e Pavia, da sempre antagoniste di Milano e che per questo motivo si erano schierate dalla parte dell'imperatore. È dunque plausibile ipotizzare il pieno sostegno del Comune ambrosiano alle iniziative dell'arcivescovo, che in qualche modo spianavano la strada all'ampliarsi della rete di alleanze facenti capo a Milano, vale a dire della Lega lombarda: non è forse un caso che le Chiese entro le quali più decisa fu l'azione di Galdino corrispondono alle località che - ancora a eccezione di Pavia e di Como - più a lungo costituirono l'ambito entro cui si esercitò sensibilmente l'influsso politico del comune di Milano, come rivela anche solo un rapido sguardo alle liste dei podestà comunali e, soprattutto, alla loro provenienza ${ }^{66}$. Galdino, dunque, anche grazie all'autorità legatizia di cui era investito, poté agire autorevolmente soprattutto nei territori situati entro l'area di influenza politica del comune ambrosiano, o in quelli in cui il comune stesso sperava di rafforzare la propria posizione.

\subsubsection{Gli altri cardinali legati}

A conferma di una divisione degli ambiti d'azione dei legati in relazione ai punti d'appoggio politici sui quali potevano fare affidamento è utile ricordare che negli anni cruciali tra 1167 e 1170 Galdino non era l'unico legato papale presente nella regione, giacché in essa nei medesimi anni agivano altri cardinali lombardi. Si tratta del bolognese Ildebrando Crassus, nel 1157, nel 1159-1169, nel $1171-1176$ e nel 1178 legato papale nelle regioni del nord-est dell'Italia settentrionale (Venezie e Romagna) ${ }^{67}$, del bresciano Oddo di S. Nicola in Carcere Tulliano, incaricato della legazione probabilmente nel gennaio del

65 Dunken (cit. nota 2) pp. 93sg. e 120sg.; Ambrosioni (cit. nota 2) p. 434; Maria Pia Alberzoni: Città, vescovi e papato nella Lombardia dei Comuni, Novara 2001, pp. $174-176$.

66 Si veda Elisa Occhipintr: Il podestariato in età comunale: flussi di esportazione e di reclutamento, in: Archivio storico lombardo 120 (1994) pp. 13-37; Enrico Artifoni: I podestà itineranti e l'area comunale piemontese. Nota su uno scambio ineguale in: I podestà dell'Italia comunale, vol. 1/1: Reclutamento e circolazione degli ufficiali forestieri (fine XII sec.-metà XIV sec.), a cura di Jean-Claude Maire Vigueur, Roma 2000 (Nuovi Studi Storici 51/Collection de l'École française de Rome 268), pp. 23-45.

67 Dunken (cit. nota 2) pp. 63, 70-78, 83-87, 103-107, 117, 128, 143; Weiss (cit. nota 5) pp. 207-212; РACAUT (cit. nota 15) pp. 833sg., sottolinea gli ampi poteri affidati al cardinale Ildebrando (legatus in tota Lombardia), un esperto giurista, che seppe dispiegare le sue capacità diplomatiche anche a sostegno e, per così dire, a integrazione della coeva azione del pragmatico Galdino. 
1170, ma che risulta attivo nell'Italia settentrionale a partire dall'autunno di quell'anno $^{68}$. Nel corso di questa legazione egli certo collaborò a consolidare le istituzioni ecclesiastiche bresciane nella fedeltà da poco riaffermata ad Alessandro III ${ }^{69}$, così pure fu in diverse occasioni al fianco di Galdino, sia a Milano, sia a Brescia, dove nel 1172 Oddo, oltre a giudicare gli ecclesiastici scismatici di quella città, intervenne per la soluzione di alcune cause ecclesiastiche relative alla diocesi e alla provincia mentre, forse sulla via del ritorno alla curia, nel novembre del 1172 fu attivo a Piacenza, assieme a un altro cardinale legato, Manfredo di S. Giorgio in Velabro ${ }^{70}$. Anche in questo caso dovette essere fondamentale l'appoggio del Comune bresciano all'azione del legato, un fatto che ne rafforzò la possibilità di intervento, resa ancor più organica dalla stretta alleanza politica che univa i due Comuni, entrambi appartenenti alla Lega lombarda.

Oddo, peraltro, aveva già svolto una legazione in Lombardia prima del 1156 con il cardinale Guido da Crema ${ }^{71}$, poi nel 1158 fu ancora presente assieme a un altro cardinale lombardo, Ardizzone da Rivoltella cardinale diacono di S. Teodoro, come inviato di Adriano IV nella regione padana per compiere una visita di carattere generale, contrassegnata da una decisa impronta politica di segno antiimperiale ${ }^{72}$.

Sempre nel decennio 1167-1176 altri cardinali lombardi svolsero almeno parte della loro attività legatizia nella regione padana. In primo luogo Guglielmo da Pavia o de Marengo, già arcidiacono della cattedrale pavese e insignito del titolo di magister, nel maggio del 1158 creato da Adriano IV cardinale prete di S. Pietro in Vincoli e alla fine di dicembre del 1176 promosso da Alessandro III cardinale vescovo di Porto $(\dagger 18 \text { gennaio } 1178)^{73}$. Questi era già stato incaricato di una legazione in Lombardia da Adriano IV nell'agosto del 1159, quindi tornò nella regione per partecipare al concilio indetto da Federico I a Pavia nel febbraio del 1160, giacché egli era stato uno degli elettori del filofedericiano

68 Dunken (cit. nota 2) pp. 87-89; Weiss (cit. nota 5) pp. 212-221, consente di apportare importanti correzioni alla cronologia proposta dal Dunken: la lettera di incarico da parte di Alessandro III risalirebbe infatti al gennaio del 1170 e i suoi interventi a Brescia sarebbero ad essa successivi.

69 PUU in Italien, vol. 5 n. 11 pp. 439sg. (1167 maggio 1); Dunken (cit. nota 2) p. 88.

70 Ibid. pp. 97 e 99-102 e Pacaut (cit. nota 15) p. 834.

71 Dunken (cit. nota 8) p. 17; IP 6/1 pp. 340-342 nn. 1 e 3.

72 Ibid. pp. 35-40 („Da die Legaten noch später in der Erzdiözese Mailand visitiert haben, kann ihre Legation schlechthin nicht eine besondere nur nach Mailand gerichtete gewesen sein, sondern hatte durchaus den Charakter einer Visitationsreise."); WeIss (cit. nota 5) p. 212.

73 Oltre alla bibliografia citata sopra, alla nota 42, si vedano i cenni in BRIXIUs (cit. nota 39) p. 60 n. 13 e pp. 118-119 nota 147 (che segnala la notizia, fornita però esclusivamente da Rahewino, circa la sua provenienza dall'Ordine cisterciense), e in ZENKer (cit. nota 39) pp. 118-123 n. 93. 
Vittore $\mathrm{IV}^{74}$. Ma già nell'ottobre del 1160 Guglielmo era passato tra i sostenitori di Alessandro III e, in stretto raccordo con questo papa, svolse le successive legazioni in Lombardia, precisamente nel 1169, nell'ottobre-novembre del 1172 , tra la metà di maggio e il mese di settembre del $1175^{75}$. Il suo soggiorno del 1169 fu decisivo per il rientro del legittimo vescovo pavese nella sua sede e la sua attività durante la sua permanenza nella regione è perlopiù documentata nella soluzione di alcune cause ecclesiastiche, soprattutto nel 1172 e nel $1175^{76}$.

Un altro cardinale collaborò attivamente con Galdino nella regione padana: il genovese Manfredo di Lavagna, cardinale diacono di S. Giorgio in Velabro, promosso nel 1173 al titolo presbiterale di S. Cecilia e nel novembre del 1176 alla sede episcopale di Preneste ${ }^{77}$. Di passaggio dall'Italia settentrionale al ritorno dalla legazione svolta tra 1168 e 1169 in Ungheria, Manfredo fu forse attivo a Modena $^{78}$, ma il suo più lungo soggiorno nella regione si colloca tra $1170 \mathrm{e}$ 1172, quando il cardinale fu impegnato a sostenere l'opera dei colleghi di legazione Oddo di S. Nicola in Carcere Tulliano e Ildebrando dei XII Apostoli ${ }^{79}$. Nella tarda primavera-estate 1170 era a Piacenza; nella primavera del 1171 nuovamente alla curia, quindi nell'autunno dello stesso anno in Liguria, dove rimase per circa un anno; nell'ottobre del 1172 era di nuovo a Piacenza, per partecipare a un incontro dei rettori della Lega e lì si trattenne per un certo periodo, come attesta la soluzione di alcune cause tra ecclesiastici ${ }^{80}$.

74 Dunken (cit. nota 2) pp. 52, 57, 90sg. e 125-127.

75 Pacaut (cit. nota 15) pp. 632-822, insiste sulle doti eminentemente diplomatiche del cardinale; Janssen (cit. nota 47) p. 65, definisce così Guglielmo: „Sicherlich der politisch begabteste und gewandteste Kardinal, über den Alexander III. derzeit verfügen konnte“, aggiungendo che proprio negli anni dello scisma la sua attività a sostegno del pontefice fu infaticabile; si veda, inoltre, WeIss (cit. nota 5) pp. 232-239, dove però non si fa cenno alle legazioni del 1169 e del 1172, poiché per queste non si sono conservati documenti originali dei legati; le notizie su queste missioni sono però desumibili da altri atti.

76 Savio (cit. nota 42) pp. 430-437; Dunken (cit. nota 2) pp. 90-92.

77 Ibid. p. 122; Brixius (cit. nota 39) p. 64 n. 17 e pp. 122sg. nota 163; Manfredo di Lavagna, cardinale diacono di S. Giorgio in Velabro (dicembre 1162), cardinale prete di S. Cecilia (settembre 1173), infine cardinale vescovo di Preneste (novembre $1176-\dagger 17$ gennaio 1178). È assai probabile che alla lunga permanenza del cardinale nella regione e all'importanza dei compiti svolti si possa far risalire l'influsso dei Fieschi, che piazzarono diversi esponenti nei capitoli cattedrali della regione, per i quali rinvio a Mauro RonZANi: Vescovi, capitoli e strategie famigliari nell'Italia comunale, in: La Chiesa e il potere politico dal Medioevo all'età contemporanea, a cura di Giorgio ChitTolini/ Giovanni Miccoli, Torino 1986 (Storia d'Italia. Annali 9), pp. 120-138, che però non accenna a tale possibilità.

78 Dunken (cit. nota 2) pp. 89-90.

79 Ibid. pp. 105-107, e WeIss (cit. nota 5) pp. 243sg.

80 Dunken (cit. nota 2) pp. 110-114 e 122. 
Ancora un cardinale lombardo, Ardizzone da Rivoltella, già suddiacono della Chiesa romana, creato da Adriano IV cardinale diacono di S. Teodoro ${ }^{81}$, che nel corso del pontificato di Adriano IV aveva svolto una legazione in Lombardia $^{82}$, nell'aprile del $1175 \mathrm{fu}$ nuovamente inviato nella regione e qui rimase a lungo, almeno fino al 1182, garantendo così la presenza di un esponente della curia romana nel delicato periodo successivo alla morte di Galdino († 18 aprile 1176) e alla sconfitta di Federico I a Legnano ${ }^{83}$. Ardizzone, però, a differenza di Galdino, non svolse il ruolo di legato permanente e nemmeno di legato in Lombardia, ma fu piuttosto impegnato come „residierender Kardinal", forse per garantire un collegamento tra Alessandro III e la Lega lombarda nel corso delle trattative che, attraverso la pace di Venezia, avrebbero portato alla pace di Costanza ${ }^{84}$.

Mi sono soffermata sull'attività di Galdino e sulle coeve presenze di cardinali, limitandomi a quelli originari dell'Italia settentrionale per evidenziare come gli interventi dell'arcivescovo abbiano riguardato perlopiù diocesi suffraganee della sede ambrosiana, mentre, nei casi di Como e Pavia, il sostegno politico di Milano che in quegli anni mirava a un rafforzamento della Lega dovette essere decisivo per garantire non solo l'efficacia, ma la stessa possibilità di azione del legato: nonostante il titolo cardinalizio unitamente a quello di arcivescovo e di legato, Galdino non avrebbe potuto svolgere una così vasta attività - così vasta da suscitare l'ammirazione del Kehr - se non avesse potuto contare sul sostegno del Comune di Milano e di quelli collegati.

Inoltre, risulta impossibile considerare adeguatamente l'azione dell'arcivescovo Galdino in quanto legato papale, senza avere presente la contemporanea e spesso congiunta attività degli altri cardinali lombardi insigniti del medesimo compito e pure presenti nella regione. Si trattò di un imponente sforzo diplomatico intrapreso da Alessandro III per contrastare la fortuna del fronte filoimperiale nell'Italia settentrionale, entro il quale svolsero un ruolo rilevante sia i legati 'stabili' - oltre a Galdino, come si è detto perlopiù attivo nella parte

81 Brixius (cit. nota 39) p. 58 n. 2 e p. 113 nota 138; ZENKER (cit. nota 39) pp. 157-159.

82 Dunken (cit. nota 2) pp. 35sg.; Ganzer (cit. nota 2) pp. 133sg.; Weiss (cit. nota 5) p. 212.

83 Oltre alla bibliografia citata sora, alla nota 41, va appena accennato che il Dunken è convinto dell'origine milanese di Ardizzone, mentre il Maleczer Papst (cit. nota 13) p. 242, lo indica come proveniente „aus der Gegend von Cremona“: Ambrosioni (cit. nota 2) p. 414, sulla scorta di Paolo Guerrini: Cronotassi biobibliografica dei cardinali, arcivescovi, vescovi e abbati regolari di origine bresciana dal secolo IX al tempo presente, in: Memorie storiche della diocesi di Brescia 25 (1958) pp. 14sg., lo ritiene bresciano; la documentazione ricordata sopra, alla nota 41 , sembra confermare il radicamento della sua famiglia tra Lodi, Bergamo e Cremona.

84 Dunken (cit. nota 2) p. 153; il Dunken aggiunge che per Lucio III il cardinale Ardizzone avrebbe nella sostanza svolto il medesimo servizio di un cardinale permanente (,ständiger Legat"). 
occidentale della regione (e della provincia metropolitica), il cardinale Ildebrando dei XII Apostoli, dal 1154 pressoché ininterrottamente presente nel settore orientale dell'Italia settentrionale ${ }^{85}$, , con gli altri cardinali originari della regione, quali Ardizzone di S. Teodoro, il pavese Guglielmo di S. Pietro in Vincoli, il bresciano Oddo di S. Nicola in carcere Tulliano, e il genovese Manfredo di S. Giorgio in Velabro. Così nel giro di appena tre-quattro anni l'intera Lombardia passò sotto il controllo di Alessandro III, fino a configurarsi come la più sicura alleata del pontefice nel conflitto ancora aperto con Federico I. Si può allora comprendere l'enfasi con la quale il Dunken in diversi passaggi del suo lavoro sottolinè̀ la valenza politica delle legazioni alessandrine, giungendo ad asserire che, grazie ad esse, „Die staufische Politik war in Oberitalien an sich schon 1170 an der Kirche und ihren Organen, den päpstlichen Legaten, gescheitert ${ }^{\star 86}$.

\subsubsection{Perché non fu rinnovata la legazione al successore di Galdino}

Il Dunken individuava ancora nel 1170 un'importante svolta nella tormentata vicenda dei rapporti tra Chiesa romana e Chiesa ambrosiana, poiché a suo parere proprio allora si sarebbe verificata la completa sottomissione di Milano alla sede apostolica, secondo modalità ancor più forti e definitive di quelle verificatesi nel 1135, a seguito dell'intervento di s. Bernardo per porre fine allo scisma e orientare Milano verso l'obbedienza a Innocenzo II $^{87}$ : nel 1170, infatti, nonostante Galdino fosse arcivescovo e legato papale, furono tre giudici delegati, precisamente l'abate del monastero di Cerreto, il preposito della canonica di Crescenzago e il suddiacono papale Giovanni Buono, a pronunciare una sentenza nella causa tra il presule e l'arciprete dei decumani (il clero milanese in cura d'anime) a motivo dell'elezione del primicerio dei decumani stessi, elezione che Galdino avrebbe voluto controllare completamente, come aveva fatto con

85 Su Ildebrando, cardinale diacono di S. Eustachio, nel 1156 promosso cardinale prete dei SS. XII Apostoli, oltre alla bibliografia indicata sopra, alla nota 39, vedi Dunken (cit. nota 2) pp. 83-87, 103-107, 117-120 (Ildebrando dal 1148 fu rettore o amministratore vescovile della chiesa di S. Giminiano di Modena); a p. 166 si precisa che Ildebrando non può propriamente essere considerato un legato permanente, giacché fino al 1178 è indicato come legato in Lombardia, e come vicarius del papa; Paul Fridolin KeHR: Kaiser Friedrich I. und Venedig während des Schismas, in: QFIAB 17 (1914) p. 233, definisce la posizione di Ildebrando nei confronti del governo di Venezia come „ständiger Nuntius bei der Republik“; Ambrosioni (cit. nota 2) pp. 338sg. e 394-396.

86 Dunken (cit. nota 2) p. 94.

87 Ibid. pp. 94sg.: „Das Jahr 1170 war auch nach anderer Richtung hin bedeutsam, denn die früher widerstrebende Erzdiözese Mailand, die stets mit Rom konkurriert hatte, wurde endgültig von der ambrosianischen Tradition getrennt." 
quelle dei vertici delle istituzioni ecclesiastiche della diocesi e della provincia ${ }^{88}$. L'affermazione del Dunken può forse essere ridimensionata sulla base di due diverse considerazioni. La prima riguarda la particolare posizione dell'arcivescovo in una causa che lo vedeva opporsi al suo clero: le controversie tra il clero - soprattutto il capitolo della cattedrale - e il vescovo della medesima diocesi richiedevano solitamente l'intervento di giudici esterni alla diocesi - altrimenti il vescovo sarebbe stato al tempo stesso giudice e parte in causa nel processo -, in primis del metropolita, in questo caso coincidente con una delle parti in causa ${ }^{89}$. L'intervento di giudici delegati papali esterni alla diocesi ambrosiana, pertanto, non può costituire un indice sicuro della diminuzione delle prerogative arcivescovili.

In secondo luogo sembra di cogliere, soprattutto in un documento vescovile del 1173, con cui Galdino, in quanto arcivescovo e legato papale, prendeva sotto la protezione della Chiesa di Milano la canonica bresciana di S. Giovanni Evangelista de foris, addirittura una smaccata imitatio delle formule presenti nella documentazione papale, indubbiamente favorita dal fatto che il documento si rifaceva esplicitamente a un privilegio di Alessandro $\mathrm{III}^{90}$. Fu forse proprio un'eccessiva imitatio dello stile di governo papale perseguita da Galdino

88 Giorgio Giulini: Memorie spettanti alla storia, al governo ed alla descrizione della città e campagna di Milano ne' secoli bassi, vol. 3, Milano $2^{\mathrm{a}}$ edizione 1855, pp. 696sg.; l'annosa causa tra l'arcivescovo e il primicerio dei decumani è stata riesaminata nelle sue fasi essenziali, fino alla conclusione avvenuta solo nel 1203, da Pogliani (cit. nota 2) pp. $5-14$.

89 Una sistematizzazione del diritto canonico in tal senso è posteriore di qualche decennio, basti qui solo ricordare il commento alla costituzione 7 del IV concilio lateranense di Joannis Tevtonici Apparatus, in: Constitutiones Concilii quarti Lateranensis una cum commentariis Glossatorum, ed. Antonio García y García, Città del Vaticano 1981 (MIC A Corpus Glossatorum 2), p. 194: Set quomodo deuoluitur hic potestas iudicandi de capitulo ad episcopum, cum episcopus sit de ipso capitulo? Est enim caput capituli, ut extra iii. de uerbor. signif. Cum clerici, extra iii. de conces. prebend. non uacant. Post electionem. Si enim episcopus non esset de capitulo sequeretur quod capitulum esset monstrum non habens caput, ergo episcopus est de capitulo, sicut ille qui preest exercitui est de ipso exercitu, ff. de hiis qui notant. infam. l. ii. (...) Ego credo quod ubicumque est episcopus de capitulo, si episcopus est negligens cum aliis, deuoluitur ius corrigendi uel eligendi ad metropolitanum.

90 PUU in Italien, vol. 5 p. 448 n. 16; l'atto è ora disponibile in una nuova edizione a cura di Michele Ansani: Le carte della canonica di S. Giovanni ,de foris' di Brescia (10871200), in: Codice diplomatico della Lombardia medievale (cit. nota 41); sul processo imitativo della diplomatica papale da parte delle cancellerie vescovili è ora punto di riferimento Othmar Hageneder: Papsturkunde und Bischofsurkunde (11.-13. Jh.), in: Die Diplomatik der Bischofsurkunde vor 1250. Referate zum VIII. Internationalen Kongreß für Diplomatik (Innsbruck, 27. September - 3. Oktober 1993), hg. von Christoph Haidacher/Werner KöFler, Innsbruck 1995, pp. 39-55; nel medesimo volume si vedano pure i contributi di Giovanna Nicolaj: Note di diplomatica vescovile italiana (secc. VIII-XIII), pp. 377-392, e di Maria Franca BArOni: La documentazione arcivescovile milanese in forma cancelleresca (secc. XI-metà XIII), pp. 305-317. 
- un motivo che peraltro lo stesso Dunken mette in luce - a suscitare la diffidenza del papa, che poteva vedere in tale atteggiamento un riemergere dell'orgoglio della sede ambrosiana, un motivo che tanto aveva ostacolato il processo di riconoscimento dell'eminente ruolo della sede apostolica anche nei confronti della Chiesa di Milano" ${ }^{91}$ Nel 1173, però, non era opportuno ridimensionare o prendere le distanze dall'azione di Galdino, pena la perdita di un importante alleato nello scontro che si profilava oramai imminente contro Federico I. Si potrebbe così comprendere perché, dopo la morte di Galdino e con la mutata situazione politica seguente alla sconfitta del Barbarossa a Legnano, la „ständige Legation“ non venne più rinnovata ad Algisio da Pirovano, il successore di Galdino, ma tale compito fu nella sostanza svolto da Ardizzone da Rivoltella ${ }^{92}$.

\section{Dai cardinali legati ai cardinali residenti: Uberto Crivelli e Pietro Diani}

Dal maggio del 1185 un altro cardinale, che già aveva svolto almeno una legazione in Lombardia, sedeva sulla cattedra di Ambrogio, il milanese Uberto Crivelli. Egli poteva vantare una carriera di tutto rispetto, sviluppatasi soprattutto nel periodo dell'esilio francese di Alessandro III, al seguito del quale egli, con gli altri ecclesiastici ambrosiani era rimasto per oltre tre anni ${ }^{93}$. Grazie alla sua formazione giuridica - Uberto aveva studiato a Bologna - egli fece una rapida e brillante carriera a Bourges, dove divenne arcidiacono e

91 Oltre al quadro generale tratteggiato da Zerbi (cit. nota 3), si veda Dunken (cit. nota 2) p. 153: „Vielleicht hatte die Ständige Legatur in Mailand trotz ihres günstigen Einflusses während des Schismas auch Nachteile gebracht, die Lucius III. als früherer Legat (Hubald von Ostia) in den verflossenen Jahren hatte kennen lernen können. Während Galdin stets als ,Legatus Apostolicae Sedis' erschien, hatte Alghisius diese Würde nicht mehr"; il Dunken, inoltre, adduce proprio l'esempio del privilegio concesso da Galdino alla chiesa di S. Giovanni Evangelista di Brescia come sintomo di un'usurpazione di prerogative della sede romana - la protezione alle chiese -, che lo stesso Galdino fino agli anni sessanta del secolo aveva costantemente richiesto ai papi, piuttosto che concedere sullo stile di quella papale.

92 Ibid. p. 153: „Für Lucius III. leistete der residierende Kardinallegat Arditio demnach die gleichen Dienste eines ständigen Legaten“; sul problema si vedano anche le osservazioni di Ambrosioni (cit. nota 2) pp. 435-442.

93 FriedlaEnder (cit. nota 11) p. 15; la carriera del cardinale è tratteggiata da Elfriede Kartusch: Das Kardinalskollegium in der Zeit von 1181-1227. Ein Beitrag zur Geschichte des Kardinalates im Mittelalter, Diss. Wien 1948, pp. 196-199; DunkeN (cit. nota 2) pp. 154sg.; Ganzer (cit. nota 2) pp. 134-136; Weiss (cit. nota 5) pp. $285 \mathrm{sg}$. (con la rettifica di un'ipotesi avanzata dal Dunken); si veda, inoltre, la bibliografia citata sopra, alle note $28-29$. 
addirittura nel 1182 fu anche eletto arcivescovo, carica che però non volle accettare $^{94}$. Dal 1168 egli era anche arcidiacono della Chiesa milanese e proprio nel 1182 fu creato cardinale prete di S. Lorenzo in Damaso da Lucio III, che nel 1183 lo incaricò della legazione nell'Italia settentrionale, dove rimase fino al luglio del 1184. Il cardinale, che nel frattempo era stato eletto vescovo di Vercelli, ma non risulta avere mai assunto anche quella carica, da Milano dove perlopiù risiedette sentenziò in diverse cause ${ }^{95}$; d'altra parte in considerazione del fatto che da quell'anno la curia papale fu a Verona è lecito ritenere che Uberto sia rimasto nell'Italia settentrionale.

Nel maggio del 1185 fu eletto arcivescovo di Milano e nel novembre del medesimo anno divenne papa con il nome di Urbano III: ciò non significò l'allontanamento dall'Italia settentrionale, giacché la curia era a Verona e lì il pontefice rimase - senza peraltro rinunciare alla carica di arcivescovo - fino al termine del suo pontificato $(\dagger 20 \text { ottobre } 1187)^{96}$.

La brillante carriera, qui appena accennata, di Uberto Crivelli consente di cogliere le linee di una tendenza affermatasi fin dallo scorcio degli anni settanta del secolo: i cardinali lombardi da allora (forse il primo caso fu quello segnalato dal Dunken di Ardizzone di S. Teodoro) effettuarono soggiorni prolungati nella città d'origine e nel territorio ad essa prossimo, quindi nelle regioni di cui avevano diretta conoscenza, talora come legati papali, ma soprattutto perché esperti di quella specifica situazione e autorevoli in essa, al di sopra dei poteri locali proprio per la dignità cardinalizia: si tratta di un eloquente indice dell'accresciuta importanza del collegio cardinalizio nel governo della Chiesa intera ${ }^{97}$. Tale orientamento della sede apostolica troverebbe conferma nel fatto che sullo scorcio del XII secolo all'interno della curia romana è possibile notare il progressivo definirsi di ambiti di interesse relativi alle diverse regioni della cristianità, per i quali era riconosciuta la competenza dei cardinali provenienti da quelle regioni, o che vi avevano effettuato lunghi soggiorni.

Le numerose missioni svolte dal piacentino Pietro Diani nella regione padana, dove risiedette perlopiù a Piacenza, sua città natale, esemplificano bene queste nuove tendenze: dapprima suddiacono papale e insignito del titolo di

94 Le informazioni sulla carriera ,francese' di Uberto Crivelli sono fornite dal suo condiscepolo Stefano di Tournai (Stephani Tornacensis Epistolae, in: Migne PL 211 col. 409 n. 121): Annamaria Ambrosioni: Due chierici milanesi del XII secolo e gli studi di diritto, in: Annals of the Archive of „Ferran Valls i Taberner's Library“ 9/10 (1991) pp. 103-118, ora in EAD. (cit. nota 2) pp. 213-228.

95 Dunken (cit. nota 2) p. 155; Ganzer (cit. nota 2) p. 135 nota 10, evidenzia che in un documento del Crivelli pubblicato da Giovanni Pietro Puricelli (sec. XVII) il luogo di emissione era: in civitate Mediolani, in palatio domini cardinalis; Alberzoni Vercelli (cit. nota 42) pp. $108-112$.

96 Grillo (cit. nota 28) pp. 313sg.; Ambrosioni (cit. nota 2) pp. 337-372.

97 Ganzer (cit. nota 54) pp. 171sg.; Maleczer Papst (cit. nota 13) pp. 336-347. 
magister, quindi dallo scorcio del 1176 preposito del capitolo della chiesa di S. Antonino di Piacenza, Pietro, nel marzo del 1185 fu creato da Lucio III cardinale diacono di S. Nicola in Carcere Tulliano e nel 1188 fu promosso da Clemente III al titolo presbiterale di S. Cecilia ${ }^{98}$.

Assieme al cardinale Soffredo di S. Maria in Via Lata - anch'egli contraddistinto dal titolo di magister - il Diani svolse una legazione per pacificare Pisa e Genova, al fine di favorire la realizzazione della crociata. Quindi dalla città ligure i due legati si spostarono in Lombardia, dove tra la fine del 1188 e la primavera del 1189, si adoperarono per mettere pace tra i comuni - un'altra condizione indispensabile per l'organizzazione della spedizione in Terra Santa. Fin dalla primavera del 1189 Soffredo tornò alla curia papale, mentre Pietro Diani continuò da solo la legazione nell'Italia settentrionale fino al termine del $1190^{99}$. Dopo aver trascorso alla curia qualche mese il Diani già nella tarda estate del 1191 era di nuovo legato papale in Lombardia ${ }^{100}$, dove soggiornò a Milano, Piacenza, Padova, Parma, Verona e Mantova, e nella regione rimase fino al maggio del 1193, per favorire la pacificazione tra $\mathrm{i}$ comuni e l'imperatore; in questa occasione egli incontrò il pieno favore di Enrico VI, col quale nel 1195 per incarico papale, dapprima assieme al cardinale Graziano dei SS. Cosma e Damiano (un altro magister) nelle Marche, quindi dall'autunno del 1195 fino all'inizio del 1196 in Germania (con il cardinale Giovanni di S. Stefano in Celiomonte) trattò per la preparazione della crociata e la predicò in accordo con l'imperatore con grande successo, così che, quando il suo collega di legazione Giovanni tornò alla curia, egli rimase alla corte imperiale e accompagnò il sovrano nel suo ritorno nel regno d'Italia; solo nell'autunno inoltrato del 1196 Pietro fu di nuovo alla curia ${ }^{101}$.

Egli, dunque, soggiornò nella regione tra 1188 e 1190 e tra 1191 e 1193. Anche in seguito il Diani fu sovente in Lombardia per svolgere un'intensa azione pacificatrice in accordo questa volta con Enrico VI. Fu infine il cardinale, fino alla sua morte, avvenuta nel 1206, a garantire e a mediare personalmente le

98 Si veda la bibliografia citata sopra, alla nota 51.

99 Maleczer Papst (cit. nota 13) p. 85; Friedlaender (cit. nota 11) pp. 48 - 50 e 58-68.

100 Egli sottoscrisse privilegi papali tra il 2 maggio e il 30 agosto 1191: MALECzex Papst (cit. nota 13) pp. 364sg. nn. 2-26; quindi fu nuovamente alla curia dal 28 maggio 1193 : ibid. p. 369 n. 109.

101 Ibid. p. 96, che, oltre a giovarsi del lavoro della FrIEDLAENDER (cit. nota 11) pp. 88-93, considera le precisazioni cronologiche suggerite da Gerhard BaAken: Die Verhandlungen zwischen Kaiser Heinrich VI. und Papst Coelestin III. in den Jahren 1195-1197, in: DA 27 (1971) pp. 457 -513. La prima sottoscrizione del Diani di ritorno dalla legazione alla curia papale è del 7 dicembre 1196. 
relazioni tra la sua città natale, Piacenza, dove risiedette a lungo anche durante il pontificato di Innocenzo III, e la sede romana ${ }^{102}$.

\section{I suddiaconi della Chiesa romana}

Il caso appena accennato del cardinale Pietro Diani si presta a introdurre un ultimo aspetto che intendo considerare: l'importante ruolo svolto dai suddiaconi della Chiesa romana in quanto esecutori delle direttive apostoliche nell'Italia settentrionale.

Il suddiaconato subì proprio a partire dal periodo della riforma dell'XI secolo un'importante evoluzione, che, non senza perduranti ambiguità, lo portò a essere talora considerato tra gli ordini maggiori - diaconato e presbiterato fino a prevedere che, nel caso di evidente utilità, un suddiacono potesse assurgere alla dignità vescovile $\mathrm{e}^{103}$. A tale ascesa contribuì certo il prestigio di alcuni suddiaconi - segnatamente dei suddiaconi della Chiesa romana -, nonché il fatto che costoro fossero talora incaricati di importanti missioni per conto del papa $^{104}$. Come ha messo in luce Reinhard Elze, in molti casi furono loro affidati delicati compiti, soprattutto legazioni, poiché essi facevano parte del clero direttamente impegnato nel servizio dei pontefici ${ }^{105}$. Più di recente Tommaso di

102 Maleczek Papst (cit. nota 13) p. 86; id.: Diani, Pietro (cit. nota 51) p. 650: l'ultima sottoscrizione del cardinale a un privilegio papale risale al 2 novembre 1206; la circostanza è considerata con il dovuto risalto da Pietro Maria CAmpi: Dell'historia ecclesiastica di Piacenza, vol.2, Piacenza 1651, pp. 94sg. Pietro, probabilmente in previsione delle lunghe e pericolose legazioni che si prospettavano, aveva chiesto fin dal 1191 o 1192 a Celestino III la licentia testandi, il più antico di questo genere di atti che si sia conservato: Agostino Paravicini Bagliani: I testamenti dei cardinali del Duecento, Roma 1980 (Miscellanea della Società Romana di storia patria 25), pp. XLIII-XLIV e 3; sugli interventi di Pietro Diani soprattutto in relazione a istituzioni ecclesiastiche vercellesi Alberzoni Vercelli (cit. nota 42) pp. 113-119.

103 Robert L. Benson: The Bishop-elect. A Study in Medieval Ecclesiastical Office, Princeton (N.Y.) 1968, pp. 64sg., e, soprattutto Roger E. Reynolds: The Subdiaconat as a Sacred and Superior Order, in: ID.: Clerics in the Early Middle Ages, Hierarchy and Image, Aldershot 1999 (Collected Studies Series 669), pp. 1-39 n. IV (First Publication).

104 Basti qui per tutti accennare alla legazione svolta nel 1056 da Ildebrando (il futuro Gregorio VII), allora suddiacono di Vittore II: WeIss (cit. nota 5) pp. 18sg. In quell'occasione il suddiacono Ildebrando presiedette come legato papale un sinodo a Chalon-sur-Saône, durante il quale vennero deposti ben sei vescovi; si tratta di un'esperienza che ben consente di cogliere l'importanza della proposizione n. 4 del «Dictatus papae».

105 Reinhard ElZE: Die päpstliche Kapelle im 12. und 13. Jahrhundert, in: ZRGKanAbt 36 (1950) pp. 145-204, qui pp. 153-157 (rist. in: ID., Päpste - Kaiser - Könige und die mittelalterliche Herrschaftssymbolik. Ausgewählte Aufsätze, a cura di Bernhard Schimmelpfennig, London 1982, pp. 145-204): „Im übrigen erscheinen sie während des 12. 
Carpegna ha sottolineato come fino alla 'serrata del collegio cardinalizio' dell'XI secolo, „i suddiaconi erano tra i maggiori dignitari della città “106. A partire dal XII secolo, forse in relazione alla notevole mobilità dei clerici per motivi di studio, si nota un certo numero di suddiaconi della Chiesa romana non romani e, tanto meno, impegnati nel servizio liturgico nelle chiese dell'Urbe, quanto piuttosto insigniti di importanti benefici nelle città di provenienza, oppure in località prossime al luogo dei loro studi, soprattutto se si trattava delle scuole di teologia del regno di Francia ${ }^{107}$. Ben presto, certo in considerazione dell'alto livello della loro cultura e dei meriti acquisiti nel servizio alla Chiesa di Roma, alcuni suddiaconi ascesero alla dignità cardinalizia, come appunto, tra quelli qui ricordati, Ardizzone da Rivoltella, Lombardo e Pietro Diani da Piacenza ${ }^{108}$.

Si trattava di chierici che avevano ricevuto l'ordinazione suddiaconale dal pontefice, pur provenendo da diverse diocesi - quello di poter ordinare chierici da qualsiasi diocesi era un diritto decisamente rivendicato fin dal "Dictatus papae» (n. 14) -, e che pertanto avrebbero potuto ricevere le successive

Jhs. an der Kurie und außerhalb, bei Legationen und in Gerichtswesen in einer den Kardinälen ähnlichen, wenn auch nachgeordneten Stellung“" (p. 154).

106 Tommaso Di Carpegna Falconieri: Il clero di Roma nel medioevo. Istituzioni e politica cittadina (secoli VIII-XIII), Roma 2002, p. 137.

107 Elze (cit. nota 105) pp. 155sg.: „Infolgedessen finden sich viele päpstliche Subdiakone seit dem Auftreten dieser Bezeichnung - als Kanoniker italienischer und französischer Kirchen".

108 Si veda, inoltre, il caso, ben documentato grazie al ricco epistolario che si è conservato, del suddiacono papale Alexius che, dal soggiorno parigino e dagli studi condotti presso $S$. Vittore a partire dalla primavera del 1159 , nonché da importanti servigi resi al papa, soprattutto da una legazione in Scozia, si attendeva una promozione cardinalizia, che sopraggiunse solo nel 1188, quando fu creato cardinale prete di S. Susanna: Papsturkunden in Frankreich N.F. 8 (cit. nota 5) pp. 62sg.; PACAUT (cit. nota 15) pp. 828sg. („Une légation est donc une étape dans le cursus qui mène des offices pontificaux au cardinalat."), e Maleczen Papst (cit. nota 13) pp. 248sg., che evidenzia i suoi legami con la famiglia romana Capocci, la medesima cui sarebbe stato legato anche il cardinale Pietro de Mizo, o Cataxius (notiamo che si sono conservate tre lettere di questo cardinale al suddiacono Alexius: Papsturkunden Frankreich N.F. 8 [cit. nota 5] nn. 58-60); l'appartenenza alla famiglia Capocci è segnalata da MaLeczek Papst (cit. nota 13) p. 248sg. Pietro fu cardinale diacono di S. Eustachio, dal 1166 cardinale prete di S. Lorenzo in Damaso; in due documenti pavesi del 1174 è denominato Cataxius (1174 luglio 9, Pavia: Le carte del monastero di San Pietro in Ciel d'Oro di Pavia, 2 [1165-1190], a cura di Ezio Barbieri/Maria Antonietta Casagrande Mazzoli/Ettore CAu, Pavia/Milano 1984, nn. 74 e 75). Lidentificazione tra Pietro de Mizo (sul quale vedi Helene Tillmann: Ricerche sull'origine dei membri del collegio cardinalizio nel secolo XII, 2/2, in: RSCI 29 [1975] pp. 365-366, che però non ricorda il nome Cataxius e ritiene il cardinale membro di una famiglia romana) e Pietro Cataxius è in WeIss (cit. nota 5) pp. 240-242, che alle pp. 262sg., mette anche in luce i motivi della vicinanza o, quanto meno, della comune formazione di Pietro de Mizo con il cardinale pavese Guglielmo di Pavia; si veda ID.: Legatenurkunde und Papsturkunde (cit. nota 5) pp. $342-344$. 
ordinazioni solo dal vescovo di Roma, al quale rimanevano direttamente soggetti; al tempo stesso acquisivano importanti privilegi e una dignità che, proprio per la loro vicinanza al papa, li collocava in una condizione particolare rispetto agli ecclesiastici locali. D'altra parte l'esenzione dalla giurisdizione diocesana loro accordata era finalizzata a garantire la più ampia disponibilità al servizio del pontefice, un motivo che attesta la sempre maggior incisività del primato papale in tutte le Chiese ${ }^{109}$. Già il Kehr aveva opportunamente richiamato l'attenzione sui suddiaconi della Chiesa romana come agenti privilegiati di Alessandro III in Lombardia e alla loro attività dedicò una certa attenzione anche Annamaria Ambrosioni, nel suo studio su Alessandro III e la Chiesa ambrosiana ${ }^{110}$.

Oltre ai già ricordati suddiaconi ascesi alla dignità cardinalizia nel corso del XII secolo, meritano di essere ricordati altri esponenti di questo gruppo attivamente impegnati all'interno dei capitoli di importanti chiese, soprattutto di cattedrali, e a noi noti perché impegnati in compiti di carattere giudiziario, sovente affidati loro dal papa ${ }^{111}$.

\subsection{Suddiaconi impegnati nelle cause giudiziarie}

Oberto da Terzago dal 1168 arciprete di Monza, nominato a questa carica dall'arcivescovo Galdino per garantirsi il controllo su una Chiesa, in precedenza segnata da forti tendenze filoimperiali ${ }^{112}$, si distinse per le competenze di carattere giuridico, come suggerisce il fatto che a lui sia stata affidata la soluzione di diverse cause giudiziarie tra ecclesiastici: oltre a una controversia da lui risolta

109 Elze (cit. nota 105) p. 156.

110 Oltre alla osservazione del KeHr (cit. nota 1) pp. 368sg.: „Dabei ist zugleich zu beachten, daß viele dieser Kardinäle selbst Lombarden waren und Pfründen in den dortigen Kirchen besaßen, z. T. sogar dauernd dort residierten. ... Auch mit lombardischen Kirchenpfründen bedachten Subdiakonen des apostolischen Stuhles wäre in diesem Zusammenhange nachzugehen. Täuscht mich nicht alles, so ist im 12. Jahrhundert kein Land von päpstlichen Agenten hohen und niedern Ranges so sehr durchsetzt gewesen als gerade die Lombardei“". Sull'importanza dei suddiaconi della Chiesa romana nelle funzioni di raccordo tra la sede apostolica e le diverse regioni, oltre a MALECZEK Papst (cit. nota 13) pp. 250sg., si veda Ambrosioni (cit. nota 2) pp. 395-398 e 435442.

111 Ardizzone da Rivoltella, quando ancora era semplicemente suddiacono della Chiesa romana fu incaricato da Eugenio III, insieme al magister Omnibonus, di risovere una lite tra il vescovo Gerardo di Bologna e l'abate Alderico di Padova (1153): Dunken (cit. nota 2) p. 16; la sentenza è stata recepita nelle decretali gregoriane (X. 2.7.2 = Aemilius Friedberg: Corpus iuris canonici, vol. 2, Leipzig 1879, col. 266).

112 Ambrosioni (cit. nota 2) p. 437. 
nel 1170 per incarico dell'arcivescovo Galdino ${ }^{113}$, ancora nel 1181 sentenziò in una lite tra i canonici della cattedrale di Piacenza e il vescovo di quella città Tedaldo, circa i diritti su una chiesa piacentina ${ }^{114}$.

Il magister Giovanni Buono da Fornovo, canonico di S. Vincenzo a Bergamo, fu anch'egli un esperto giurista, come si evince dagli incarichi che ricevette: nel $1170 \mathrm{fu}$ uno dei tre giudici delegati papali impegnati nella soluzione della già ricordata causa tra Galdino e il clero decumano per l'elezione del primicerio ${ }^{115}$, quindi, nel 1174, svolse un importante ruolo in una controversia tra il vescovo di Lodi e il preposito della basilica di S. Nazaro di Milano $^{116}$. Lo stesso suddiacono, inoltre, tra 1170 e 1172 era stato incaricato di procedere materialmente alla restituzione di una notevole somma di denaro, a suo tempo mutuata ad Alessandro III dal piacentino Giovanni Grasso: il cardinale Manfredo di S. Giorgio in Velabro avrebbe dovuto consegnare il denaro al vescovo di Piacenza, che, a sua volta, per il tramite di Giovanni Buono, lo avrebbe destinato al creditore ${ }^{117}$.

Ancora grazie alla documentazione dell'Italia Pontificia emergono indicazioni circa il suddiacono lodigiano Ugo, incaricato da Celestino III nel 1193 di emanare gravi sanzioni disciplinari nei confronti del vescovo di Pavia, Lanfranco, nel caso in cui questi non avesse osservato la sentenza a lui sfavorevole circa il godimento delle decime di Port'Albera, una località contesa con la vicina diocesi di Piacenza ${ }^{118}$.

\subsection{I suddiaconi incaricati dal papa di svolgere legazioni}

Tra i suddiaconi papali presenti nelle Chiese lombarde è possibile individuare almeno due casi di incarichi legatizi. Alberto da Somma, suddiacono papale nonché nipote del cardinale vescovo di Ostia Guido da Somma, nella tarda estate e nell'autunno del 1177 svolse una legazione in Lombardia ${ }^{119}$. Nel 1178 fu inviato in Inghilterra per invitare i vescovi inglesi al Concilio lateranense ${ }^{120}$. Ancora per incarico di Alessandro III egli nel 1179-1180 fu nuovamente

113 Vedi sotto, nota 129.

114 PUU in Italien, vol. 2 p. 274 n. 38: la sentenza, pronunciata da Oberto assieme all'arcidiacono della Chiesa milanese Uberto Crivelli, fu approvata da Lucio III il 3 ottobre 1182.

115 Vedi sopra, nota 88; Giulini (cit. nota 88) III, p. 696 (edizione in ibid. 7, p. 131).

116 Dunken (cit. nota 2) p. 95; Ambrosioni (cit. nota 2) p. 437.

117 PUU in Italien, vol. 2 p. 264 n. 26; DUNKEN (cit. nota 2) p. 110.

118 PUU in Italien, vol. 2 pp. $284-285$ n. 48.

119 Dunken (cit. nota 2) pp. 140sg.; Pacaut (cit. nota 15) p. 828; Weiss (cit. nota 5) p. 269.

120 Ambrosioni (cit. nota 2) p. 438; Weiss (cit. nota 5) p. 269. 
inviato nell'Italia settentrionale, precisamente a Venezia, ma durante il suo viaggio toccò anche la Lombardia orientale, segnatamente Brescia, nonché alcune città della Lombardia occidentale, come fa suppore il suo intervento (13 luglio 1180) presso i vescovi di Tortona, Piacenza, Cremona e Parma in favore del monastero pavese di S. Maria Teodote ${ }^{121}$. Il 10 ottobre, a Venezia, egli ricevette istruzioni per recapitare ai rettori della Lega lombarda le lettere di Federico I in merito alle trattative di pace con Alessandro III e i cardinali; il 22 dello stesso mese era a Parma, dove espose le richieste dell'imperatore ai consoli di Milano, Piacenza e Alessandria. In seguito fu anche a Novara, dove si occupò di alcune questioni relative all'amministrazione della diocesi e al pagamento del censo alla Chiesa romana ${ }^{122}$.

Un altro suddiacono papale, Sicardo, pure lui esperto di diritto e teologia, che aveva studiato forse a Colonia alla scuola del suo concittadino Prepositino, quindi a Bologna, svolse almeno una legazione per conto di Lucio III in Germania ${ }^{123}$, il medesimo pontefice che, secondo la personale testimonianza di Sicardo, nel 1183 lo aveva ordinato suddiacono ${ }^{124}$. La carriera di Sicardo ebbe importanti sviluppi in sede locale, giacché egli nel 1185 fu eletto vescovo di Cremona e fu poi incaricato da Urbano III nel dicembre del 1185 di svolgere una legazione in Lombardia - legazione che si protrasse fino al giugno dell'anno successivo $^{125}$-, un incarico che gli fu rinnovato nel 1212 da Innocenzo III, questa volta per contrastare, unitamente ad Ariprando Visconti, un altro vescovo proveniente dalle file dei suddiaconi papali e insignito della legazione, la politica di Ottone di Braunschweig in Lombardia ${ }^{126}$.

121 Dunken (cit. nota 2) p. 148.

122 IP 6/2 p. 60 n. 7; Ambrosioni (cit. nota 2) p. 397; EAd.: Un documento sulla vita comune dei canonici di S. Ambrogio, in: Contributi dell'Istituto di Storia Medioevale, vol. 3, a cura di Pietro Zerbi, Milano 1975 (Scienze storiche 12), pp. 3-28, ora in Ambrosioni (cit. nota 2) pp. 156-159, nello stesso volume si vedano anche le pp. 378, 381, 438sg.

123 Dunken (cit. nota 2) pp. 158-160; Oswald Holder-Egger: De vita Sicardi, in: MGH SS 31, Hannover/Leipzig 1902, pp. 22-59; su di lui Ch. LefEBvre in: DDC 7 (1965) coll. 1008-1011; Giorgio PicAsso in: Dictionnaire de spiritualité 14 (1988) coll. 810-814; André VAuchez: Innocent III, Sicard de Crémone et la canonisation de saint Homebon ( $\dagger$ 1197), in: Innocenzo III (cit. nota 51) pp. 435-453; Edward Coleman: Sicard of Cremone as Legate of Innocent III in Lombardy, in: Innocenzo III (cit. nota 51) pp. 929-953.

124 Non sono frequenti notizie sulle ordinazioni suddiaconali da parte dei pontefici, come nota Elze (cit. nota 105) pp. 155sg. nota 63.

125 Dunken (cit. nota 2) pp. 159sg.; sul lungo episcopato di Sicardo, mi limito a rinviare a Savio (cit. nota 42) pp. 94-121.

126 Alberzoni Città (cit. nota 65) pp. 71-73. 


\subsection{I suddiaconi nei capitoli delle cattedrali}

Sarebbe indubbiamente utile avviare un censimento dei suddiaconi della Chiesa romana che nel XII secolo ottennero cariche di rilievo all'interno dei capitoli di cattedrali o di importanti chiese ${ }^{127}$, ma il compito è reso oltremodo arduo dal fatto che spesso le menzioni nei documenti o le sottoscrizioni non riportano tutte le dignità ricoperte: si tratta di un problema analogo a quello che si pone qualora si voglia indagare sul titolo di magister ${ }^{128}$. Basti qui esemplificare con due significativi casi. Il primo è offerto da un documento contenente la già ricordata sentenza pronunciata nel luglio del 1170, per incarico dell'arcivescovo Galdino, dal suddiacono della Chiesa romana Oberto, che nel testo della sentenza dichiara di essere Sancte Romane Ecclesie subdiaconus et Modoeciensis archipresbiter, mentre nella sottoscrizione si trova solo: Ego Obertus subdiaconus et Modoetiensis ecclesie minister subscripsi ${ }^{129}$. Un secondo esempio si colloca verso la fine del secolo: ancora a Milano, tra i sottoscrittori a un diploma

127 Accanto ai tre casi ricordati da Elze (cit. nota 105) p. 156 nota 67 (Oberto da Terzago a Monza, Paolo Scolari a S. Maria Maggiore a Roma e a un non ricordato arciprete di S. Angelo), si aggiungano quelli menzionati da Ambrosioni (cit. nota 2) 397sg. Mi limito qui a segnalare almeno altri quattro casi: 1) il magister Giovanni Buono da Fornovo, che in una sentenza emessa dal vescovo di Bergamo Guala nell'agosto del 1174 è indicato come domini pape subdiaconus e canonico della chiesa di Bergamo; 2) un non meglio identificato prepositus Sancti Prosperi (Reggio Emilia), indicato da Celestino III come subdiaconus noster (1192 aprile 23: Julius von Pflugk-Harttung: Acta pontificum Romanorum inedita, vol. 3, Stuttgart 1886, p. 383 n. 447); 3) il magister Aicardo di Burolo, preposito del capitolo di Ivrea almeno dal 16 luglio 1196, quando Celestino III confermò una sentenza del vescovo di Tortona: Le carte dell'Archivio capitolare (cit. nota 42) pp. 183-184 n. DCXXXIII (il documento è edito anche in PUU in Italien 3 pp. $138-139$ n. 24); nel corso di questa controversia Aicardo era procuratore dei chierici di S. Nazaro e fu forse proprio lui a recarsi presso la corte papale per ottenere la conferma della sentenza. Un'altra importante attestazione su Aicardo è in una lettera del primo anno di pontificato di Innocenzo III (Die Register Innocenz' III., 1: 1. Pontifikatsjahr, 1198/1199. Texte, bearbeitet von Othmar Hageneder/Anton Haidacher, Graz/Köln 1964 [Publikationen der Abteilung für historische Studien des Österreichischen Kulturinstituts in Rom 2/1], p. 62 n. 40), che consente di cogliere un incarico affidato ad Aicardo da Celestino III: Preterea dilectis filiis Aicardo Yporiensi et magistro Marescoto canonice Gualteri prepositis, Romane ecclesie subdiaconis, dedit ipse predecessor noster firmiter in mandatis; il relativo documento di Celestino III è indicato in IP 6/2 p. 67 n. *29 (sulla base del Registro di Innocenzo III; infine 4) magister Marescotus, preposito della canonica pavese di S. Maria Gualtieri; si vedano, inoltre, sotto (note 133sg. e 141 e testo corrispondente) i casi di Oldeberto Tornielli, Giovanni Tornielli e Obizo de Castello, canonici di Novara; di Guglielmo Balbo e di Alberto Amicone (vedi sotto, note $139-145)$.

128 Rainer Maria Herkenrath: Studien zum Magistertitel in der frühen Stauferzeit, in: MIÖG 88 (1980) pp. 3-35.

129 Edizione a cura di Michele Ansani: Codice diplomatico della Lombardia medievale (cit. nota 41), Milano, S. Vittore al Corpo, n. 3. 
dell'arcivescovo Filippo da Lampugnano del 22 ottobre 1197 compaiono i domini Ariprando Visconti ed Enrico da Settala, designati in quella occasione come subdiaconi iamdicte ecclesie, vale a dire della Chiesa di Milano ${ }^{130}$. In realtà, grazie alla documentazione di provenienza papale, sappiamo che entrambi i chierici erano suddiaconi della Chiesa romana ${ }^{131}$.

Un suddiacono papale poteva accedere a una dignità capitolare qualora avesse ottenuto validi appoggi in sede locale, ma soprattutto presso la curia papale, come è possibile cogliere grazie a una lettera di Innocenzo III, che riferisce in modo dettagliato una causa giudiziaria vertente sul conseguimento di un beneficio nella cattedrale di Novara. Il 5 marzo del 1198, due settimane dopo la consacrazione papale, Innocenzo III incaricava il vescovo di Lodi di risolvere una questione dibattuta tra il capitolo della Chiesa di Novara e il chierico Alberto Siccus ${ }^{132}$. Quest'ultimo, grazie alla mediazione di suo fratello Giacomo, nel 1196 aveva ottenuto da Celestino III una lettera di raccomandazione presso il vescovo di Novara Oberto, che, in accordo con il capitolo, aveva assegnato un beneficio ad Alberto; e questi da allora in eadem ecclesia stetit, cantavit et legit et cum aliis divina officia celebravit. Il capitolo aveva addirittura inviato alla curia il dilectus filius Obizo de Castello, suddiacono papale e canonico di Novara, che aveva ottenuto sempre da Celestino III la conferma della nomina. Ma nel medesimo anno un canonico di Novara, il magister Ugo de Racaneto, fu eletto vescovo di Squillace in Calabria, un fatto di cui Giacomo e Alberto Sicco dichiararono di essere rimasti all'oscuro, e la prebenda di Ugo fu assegnata da Celestino III, dietro richiesta di alcuni cardinali e dell'imperatore, al suddiacono papale Giovanni Tornielli ${ }^{133}$.

130 Giulini (cit. nota 88) vol. 4 p. 94.

131 Per Ariprando: Die Register Innocenz' III., 5: 5. Pontifikatsjahr, 1202/1203. Texte, bearbeitet von Othmar Hageneder unter Mitarbeit von Christoph EgGer/Karl Rudolf/Andrea Sommerlechner, Wien 1993 (Publikationen des Historischen Instituts beim Österreichischen Kulturinstitut in Rom 2/5), p. 283 n. 143 (144): 1203 gennaio 19, Innocenzo III ordina al capitolo di Novara di assegnare una prebenda vacante dilecto filio Alibrando Vicecomiti, subdiacono nostro, Mediolanensi ordinario, quem virum esse novimus providum et discretum et tam scientia quam moribus adornatum; per Enrico da Settala: Register I (cit. nota 109) p. 183 n. 120: dilectus filius Henricus, subdiaconus noster, pro te (l'arcivescovo Filippo da Lampugnano) tam apud sedem apostolicam quam alias fideliter laboraverit: 1198 aprile, Innocenzo III ordina all'arcivescovo di Milano di assegnare a Enrico da Settala la carica vacante di cancelliere della Chiesa di Milano.

132 Hageneder (cit. nota 127) pp. 61-64 n. 40.

133 Ibid. p. 62: Cumque magister Hugo de Racaneto, eiusdem ecclesie tunc canonicus, in Calabria factus fuisset episcopus tempore procedente, ipso Jacobo et fratre suo promotionem suam penitus ignorantibus, dilectus filius Johannes Torniellus, subdiaconus noster, fuit de prebenda prefati Hugonis per predictum predecessorem nostrum ad preces imperiales et quorundam cardinalium investitus. 
Intanto il vescovo di Novara morì e gli successe il magister Pietro, già canonico della cattedrale, così che si liberò una prebenda che fu subito rivendicata sia da Giacomo, che riteneva fosse di diritto di suo fratello Alberto, sia da Giovanni; la complessa causa fu infine portata al cospetto di Celestino III, che, dopo aver sentito il parere dei cardinali, aveva infine assegnato la prebenda ad Alberto, lo aveva investito per anulum, e aveva rilasciato delle lettere per rafforzare la decisione presa e smorzare le resistenze di alcuni membri del capitolo, che continuavano a sostenere la candidatura del Tornielli. Celestino III aveva quindi incaricato due suddiaconi papali di sua fiducia, Aicardo di Ivrea e Marescotto, rispettivamente prepositi della cattedrale di Ivrea e della canonica Gualtieri di Pavia, di far rispettare la decisione papale dal capitolo di Novara, eventualmente servendosi di censure ecclesiastiche.

Senza voler qui esaminare ulteriormente l'andamento della causa, mi limito a notare quanto la lettera innocenziana consenta di cogliere, certo in via approssimativa, circa la consistente presenza dei suddiaconi papali all'interno dei capitoli cattedrali: lo stesso Giovanni Tornielli, che dal 1190 era già canonico nella concattedrale novarese di S. Gaudenzio, e che prima del 1206 ottenne anche l'ambito canonicato in S. Maria, fu poi eletto vescovo di Bergamo nell'autuno del $1211^{134}$.

In secondo luogo la missiva innocenziana risulta particolarmente istruttiva circa le modalità che consentivano ai suddiaconi di ottenere posti nei capitoli delle cattedrali: Celestino III era stato sollecitato a intervenire in favore del Tornielli dalle preghiere rivoltegli dall'imperatore Enrico VI e da alcuni cardinali, di cui non sono indicati i nomi. Ritengo, però che in questo caso sia possibile avanzare qualche fondata ipotesi: proprio nel 1196 il cardinale Pietro Diani tornava dalla legazione svolta nel regno di Germania e, infatti, raggiunse la curia solo nell'ottobre di quell'anno. Con lui era venuto nella penisola anche l'imperatore Enrico VI, che nel novembre, mentre ancora era a Tivoli fu raggiunto dal Diani, oramai divenuto un uomo di fiducia della corte imperiale, dal camerario Cencio e dal cardinale Ottaviano d'Ostia, inviati dal papa per proseguire le trattative con l'imperatore ${ }^{135}$. Ebbene: prima di giungere alla curia, Pietro Diani aveva soggiornato a Torino, Milano e Piacenza ${ }^{136}$, quindi doveva essere transitato da Novara, dove è probabile che i potenti congiunti del Tornielli, tra i quali era anche il vescovo di Acqui Ugo Tornielli - vescovo e al

134 Thomas Behrmann: Domkapitel und Schriftlichkeit in Novara (11.-13. Jahrhundert). Sozial- und Wirtschaftsgeschichte von S. Maria und S. Gaudenzio im Spiegel der urkundlichen Überlieferung, Tübingen 1994 (Bibliothek des Deutschen Historischen Instituts in Rom 77), pp. 57 e 297.

135 Maleczer Papst (cit. nota 13) p. 86.

136 Friedlaender (cit. nota 11) p. 97. 
tempo stesso arcidiacono della cattedrale di S. Maria di Novara -, gli abbiano avanzato la richiesta e abbiano ottenuto che fosse appoggiata presso il papa ${ }^{137}$.

Oltre ai meriti di studio erano dunque indispensabili consistenti appoggi da parte di prelati o di personaggi di alto rango, che consentivano di affermare per così dire anche in loco la posizione privilegiata dei suddiaconi della Chiesa romana.

\subsection{Filippo da Lampugnano e l'ordinazione dei suddiaconi}

Negli ultimi decenni del XII secolo il numero dei suddiaconi della Chiesa romana sembra decisamente lievitare, sia in relazione agli incarichi da loro svolti per conto del papa, sia per le brillanti carriere ad essi riservate in sede locale come pure alla curia romana ${ }^{138}$; non si può peraltro escludere che l'emergere più frequente di notizie a loro proposito sia dovuto alla più abbondante tradizione documentaria. Oltre al già ricordato Sicardo di Cremona una nutrita schiera di futuri vescovi lombardi proveniva dal gruppo dei suddiaconi papali: i milanesi Uberto da Pirovano, canonico di Monza e magister, dal 1206 cardinale diacono di S. Angelo, quindi arcivescovo di Milano ${ }^{139}$; il già ricordato Ariprando Visconti, ordinario della Chiesa di Milano, nonché canonico della cattedrale di Novara, poi vescovo di Vercelli e legato papale di Innocenzo III assieme a Sicardo di Cremona ${ }^{140}$; Enrico da Settala, cimiliarca della Chiesa ambrosiana e

137 La famiglia Tornielli è indicata da Behrmann (cit. nota 134) passim, come la meglio rappresentata nei capitoli novaresi a partire dal XII secolo; era sicuramente una famiglia con buone disponibilità finanziarie, così che in alcune occasioni concesse mutui in denaro ai canonici novaresi. Ugo era presente fin dal 1172 nel capitolo di S. Maria, del quale mantenne la dignità di arcidiacono anche durante il suo episcopato, e come arcidiacono della cattedrale concluse i suoi giorni, dopo che nel 1213 fu costretto a dimettersi da vescovo di Acqui-Alessandria: Alberzoni Città (cit. nota 65) pp. 173211; EAD.: I „mercatores Romani“ nel Registro di Innocenzo III, in: La storia e la memoria. In onore di Arnold Esch, a cura di Roberto Delle Donne/Andrea Zorzi, Firenze 2002, pp. 91-108.

138 Assai istruttiva è la corrispondenza relativa al suddiacono papale Alexius, al quale fin dal 1168 fu fatta balenare un'importante promozione presso la curia, probabilmente il suo ingresso nel collegio cardinalizio, per il quale avevano lavorato a lungo, oltre ai suoi parenti già presenti nel collegio cardinalizio, il cardinale Giacinto e il cardinale Guglielmo da Pavia, il quale pure aveva trascorso un lungo periodo a S. Vittore: Papsturkunden Frankreich N. F. 8 (cit. nota 5) nn. 67 e 99-102.

139 Ganzer (cit. nota 2) pp. 152sg.; Maleczek Papst (cit. nota 13) pp. 153sg.; Maria Pia Alberzoni: Hubert de Pirovano, in: DHGE 25 (1995) coll. 14-17.

140 Vedi sopra, note 126 e 130sg.; Ariprando Visconti, ordinario della Chiesa milanese, nel settembre del $1203 \mathrm{fu}$ attivo come procuratore degli ordinari della Chiesa milanese nella causa che li vedeva opposti al clero decumano della medesima città: Pogliani (cit. nota 2) pp. 84sg.; almeno dal 1203 era anche canonico di S. Maria di Novara: BeHrmann (cit. nota 134) pp. 60 e 270, dal 1208 al 1213 vescovo di Vercelli (Fedele SAvio: Gli 
nel 1213 nominato arcivescovo dal pontefice ${ }^{141}$; i novaresi Oldeberto Tornielli, dal 1185 presente nel capitolo della cattedrale di S. Maria di Novara e dal 1215 vescovo di quella città, e suo nipote Giovanni, dal 1190 nel capitolo novarese di S. Gaudenzio e dal 1211 vescovo di Bergamo ${ }^{142}$. Ad essi se ne possono aggiungere numerosi altri, che solo un'attenta indagine, soprattutto del clero cattedrale, potrà rivelare a pieno. Mi limito qui a ricordare ancora Guglielmo Balbo, suddiacono papale e ordinario della Chiesa milanese, anch'egli distintosi per indubbie capacità e conoscenze in campo giuridico, sovente impegnato come giudice delegato papale, e, soprattutto procuratore dell'arcivescovo Filippo da Lampugnano nell'annosa causa che fu dibattuta alla curia per il riconoscimento di importanti diritti della cattedra ambrosiana sul monastero di Scozola presso Sesto Calende ${ }^{143}$, dal 1201 arciprete della Chiesa milanese ${ }^{144}$. Alberto Amicone, nel capitolo della Chiesa ambrosiana almeno dal 1197 e nel 1213 successore di Guglielmo Balbo nella dignità di arciprete ${ }^{145}$.

Il loro numero e la loro fortuna aumentarono almeno fino al pontificato di Innocenzo III, il quale, a sua volta, probabilmente a Bologna, o comunque in quella regione, nel 1187 aveva ricevuto l'ordinazione suddiaconale da Gregorio VIII $^{146}$. Innocenzo III, infatti, ancor prima della sua consacrazione a vescovo di Roma, nel febbraio del 1198 dovette affrontare una richiesta dell'arcivescovo di Milano Filippo da Lampugnano, che riteneva necessario poter procedere alla consacrazione agli ordini sacri dei numerosi suddiaconi papali presenti tra il

antichi vescovi d'Italia dalle origini al 1300 descritti per regioni. Il Piemonte, Torino 1898, p. 488) e dal 1212 legato papale assieme a Sicardo di Cremona: Alberzoni Città (cit. nota 65) pp. 181sg. e 186-190.

141 Maria Pia Alberzoni: Henri de Settala, in: DHGE 23 (1990) coll. 1227-1230.

142 Behrmann (cit. nota 134) pp. 34, 57, 297, 308 (albero genealogico della famiglia); SAvio (cit. nota 138) pp. 275sg. (Oldeberto) e id.: Gli antichi vescovi d'Italia dalle origini al 1300 descritti per regioni. La Lombardia, 2/1: Bergamo - Brescia - Como, Bergamo 1929, pp. 88-99 (per Giovanni); le difficoltà incontrate da Giovanni per vedersi riconoscere la prebenda nel capitolo di S. Maria sono accennate sopra, note 132 133.

143 Die Register Innocenz' III., 2: 2. Pontifikatsjahr, 1199/1200. Texte, bearbeitet von Othmar Hageneder/Werner Maleczek/Alfred A. Strnad, Rom/Wien 1979 (Publikationen des Österreichischen Kulturinstituts in Rom 2/2), pp. 60-66 n. 37 (1199 aprile 16); Gesta Innocentii PP III, in: Migne PL 214 coll. LXXXIVsg.; sull'attività di Guglielmo Balbo, soprattutto come giudice delegato papale: Alberzoni Città (cit. nota 65) pp. 108sg., 181, 186-189, 232, 237.

144 Pogliani (cit. nota 2) passim. Si vedano, inoltre, i casi ricordati sopra, alla nota 127. 145 Fedele SAvio: Gli antichi vescovi d'Italia dalle origini al 1300 descritti per regioni. La Lombardia, 1: Milano, Firenze 1913, p. 567.

146 La notizia è nei Gesta Innocentii (cit. nota 143) col. XVIII: Hunc (Lotharium) sanctae memoriae Gregorius octavus papa in subdiaconum ordinavit; Wilhelm Iмкамр: Das Kirchenbild Innocenz III. (1198-1216), Stuttgart 1983 (Päpste und Papsttum 22), p. 23; Werner Maleczek: Innocenzo III, in: Enciclopedia dei papi (cit. nota 21) pp. 326350 . 
clero della sua diocesi ${ }^{147}$. Il presule doveva aver prospettato una situazione drammatica, nella quale egli si sarebbe trovato addirittura in difficoltà a trovare chierici degni della promozione che non avessero già ricevuto un'ordinazione dal papa - presumibilmente quella suddiaconale - e che, quindi, in quanto incardinati nel clero romano, pur essendo residenti nella diocesi ambrosiana, sarebbero potuti divenire diaconi o presbiteri solo grazie all'imposizione delle mani del vescovo di Roma ${ }^{148}$. Con buona probabilità tale forte concentrazione di chierici legati alla sede apostolica doveva verificarsi tra il clero della cattedrale, anche se la loro precisa entità è difficilmente valutabile sulla base delle sottoscrizioni ai documenti arcivescovili.

Innocenzo III rispondeva positivamente alla petizione dell'arcivescovo e gli concedeva di procedere auctoritate nostra alle ordinazioni di coloro che fossero risultati idonei e che avessero manifestato la loro volontà di ascendere al diaconato o al presbiterato ${ }^{149}$, altrimenti - evidentemente nel caso i suddiaconi avessero manifestato qualche resistenza ad accedere al diaconato - il presule avrebbe dovuto segnalare in una lettera al papa quali altri chierici 'romani' a suo parere potevano essere ritenuti idonei e necessari; in questo caso il pontefice si riservava di deliberare in merito e di far quindi giungere all'arcivescovo le indicazioni sul da farsi ${ }^{150}$.

A prescindere da considerazioni che suggerirebbero la volontà dell'arcivescovo di riprendere l'iniziativa in vista di un maggior controllo sul clero della sua diocesi, la situazione della Chiesa di Milano ministrorum solacio destituta, come descritta nella lettera innocenziana, può essere considerata non molto lontana dalla realtà: nel capitolo della cattedrale i suddiaconi dovevano essere realmente numerosi e così diveniva difficile promuovere agli ordini sacri coloro che ne

147 Hageneder (cit. nota 127) pp. 33sg. n. 22; Elze (cit. nota 105) pp. 168-171; Maria Pia Alberzoni: Lampugnano, Filippo da, in: DBI 63 (2004) pp. 285-288.

148 Hageneder (cit. nota 127) pp. 33sg. n. 22: Inde est, quod - sicut ex tuarum tenore litterarum accepimus - Mediolanensis ecclesia tam in capite quam in membris occasione clericorum illorum, qui ab ipso Romano pontifice ordinem receperunt, adeo est ministrorum solacio destituta, ut paucos clericos in eadem ecclesia valeas invenire, quos ad diaconatus et presbyteratus possis officium promovere.

149 Ibid. p. 34: Verum quia fraternitas tua suppliciter a nobis expetiit, ut ipsius ecclesie necessitatem sollicitudine paterna pensantes tibi deberemus licentiam indulgere manus posse illis ordinatione imponere.

150 Ibid.: Super hoc tue fraternitati taliter duximus respondendum, quod ipsius ecclesie necessitate pensata, si aliqui fuerint de supradictis clericis, qui ad hoc videntur idonei et spontanea voluntate per tuum ministerium voluerint ad sacros ordines promoveri, eos auctoritate nostra tibi liceat ordinare. Alioquin illos, quos ad officium illud magis idoneos ac necessarios fore noveris, nobis per tuas litteras significare curabis. Nos enim deliberato consilio respondebimus, quid tibi super hoc fuerit faciendum. Desidero qui esprimere la mia gratitudine al dottor Martin Bertram (Deutsches Historisches Institut in Rom) per i validi consigli offertimi nell'interpretazione di questo testo. 
avrebbero abbisognato per ricoprire le dignità capitolari ${ }^{151}$. A puro titolo esemplificativo ricordo i numerosi casi di arcipreti o prepositi che si intitolano suddiaconi della Chiea romana, un chiaro indizio che non avevano ancora ricevuto gli ordini maggiori, proprio perché il loro conferimento dipendeva dal vescovo di Roma. Tra questi casi si segnala quello di Oberto da Terzago, presente nel capitolo di Milano fin dal 1168, designato dall'arcivescovo Galdino arciprete di Monza, quindi dal 1194 anche arcidiacono della cattedrale di Milano, tra settembre 1195 e giugno 1196 arcivescovo di Milano: si ha l'impressione che la ragguardevole carriera di questo chierico dovette essere coronata dall'ordinazione presbiterale solo in un periodo di tempo prossimo all'elezione episcopale, un caso che certo non poteva passare inosservato e non suscitare perplessità nel suo successore sulla cattedra di Ambrogio, il magister Filippo da Lampugnano ${ }^{152}$.

Il fatto che i suddiaconi papali godessero di consistenti benefici nei capitoli di importanti chiese e poi non fossero in grado di adempiere ai compiti richiesti dalla dignità ricoperta fu motivo di attriti, sia all'interno dei collegi canonicali, sia tra capitoli e vescovi. Reinhard Elze ha inoltre indicato proprio nell'alto numero dei suddiaconi papali non residenti presso la curia romana e nei problemi derivanti dal loro approvvigionamento con benefici nelle Chiese locali uno dei motivi di scontento dei vescovi. L'esenzione dei suddiaconi papali dalla

151 Accenno qui a qualche esempio delle difficoltà nell'individuare con sicurezza i suddiaconi papali presenti nei capitoli delle cattedrali: 1) in un privilegio dell'arcivescovo Robaldo (1143-1144), al primo posto dopo l'arcivescovo compare Galdinus, cancellarius, il futuro arcivescovo; nel giugno del medesimo anno, lo stesso Galdino sottoscriveva un privilegio arcivescovile come Galdinus subdiaconus et cancellarius (in: Codice diplomatico della Lombardia medievale [cit. nota 41], ed. a cura di Ada Grossi/ Maria Franca BARONI); notiamo che negli stessi documenti emerge anche che un'altra importante carica - quella di tesoriere - era ricoperta da un suddiacono: Obitius subdiaconus et cimiliarca. 2) In un diploma dell'arcivescovo Filippo da Lampugnano (1197), pubblicato in GiULINI (cit. nota 88) 7, pp. 146-147, tra i sottoscrittori figurano tre suddiaconi, Lanterio da Lampugnano (un parente dell'arcivescovo), Ugo da Settala (appartenente alla stessa famiglia di un altro suddiacono papale, Enrico, nel 1213 nominato da Innocenzo III arcivescovo di Milano) e Alberto. L'appartenenza di quest' ultimo al gruppo dei suddiaconi papali è chiarita da una lettera di Innocenzo III del 6 febbraio 1201, indirizzata all'abate del monastero di S. Ambrogio e ad Alberto Amicono, subdiacono nostro canonico Mediolanensi (l'edizione in Werner MALECzen: La pieve di Casorate nella controversia con il monastero cisterciense di Morimondo. Un contributo sulla giurisdizione papale delegata al tempo di Innocenzo III, in: Archivio storico lombardo 123 [1997] p. 318); è dunque dalla documentazione papale che possiamo evincere notizie più sicure.

152 Renato Mambretti: Oberto da Terzago arcivescovo di Milano, in: Ricerche storiche sulla Chiesa ambrosiana (cit. nota 2) pp. 112-143 (in particolare 132); Liber Ordinarius Modoetiensis cum Kalendario-Obituario, Tomus B, ed. Renatus MambretTI, Roma 2001 (Bibliotheca „Ephemerides liturgicae. Subsidia“ 117), pp. 226-228. 
giurisdizione episcopale creava sovente attriti, come è ancora possibile evincere da una lettera di Innocenzo III al vescovo di Firenze, che nel 1206 ottenne di riportare all'obbedienza nei suoi confronti i suddiaconi papali che detenevano benefici di quella Chiesa, ma solo per quanto riguardava i doveri inerenti ai benefici stessi. È infatti assai incisiva la precisazione del papa, che, nel concedere al vescovo di pretendere obbedienza dai suddiaconi per quanto riguardava gli obblighi liturgici, non tralasciava di ricordare la particolare posizione dei suddiaconi: ut illis specialiter quantum convenit a te inter alios tibi subditos deferatur, quos benignitas apostolica collatione ispsius ordinis honoravit ${ }^{153}$. Il suddiacono della Chiesa romana, anche se non residente alla curia papale, era dunque da ritenersi in una condizione privilegiata, proprio in considerazione del suo legame istituzionale con il vescovo di Roma.

La presenza di suddiaconi della Chiesa romana nelle diverse Chiese locali si configura dunque come un fenomeno degno di attenzione per comprendere i modi e i tempi degli interventi papali all'interno delle diocesi. Se infatti a partire dalla fine dell'XI secolo il loro servizio ai pontefici si espresse soprattutto nell'adempimento di importanti funzioni diplomatiche, talora di carattere dichiaratamente politico, nel corso del XII secolo si nota un incremento della loro presenza stabile all'interno delle istituzioni ecclesiastiche diocesane, con importanti compiti di raccordo tra la sede romana e le Chiese particolari: da una parte, infatti, essi potevano controllare da vicino le decisioni dei vescovi e dei capitoli delle cattedrali e denunciare prontamente alla sede romana le eventuali inosservanze della normativa canonica; dall'altra essi erano utili agli stessi vescovi e ai capitoli per avere un canale preferenziale di accesso alla sede apostolica, presso la quale i suddiaconi papali erano sovente inviati come procuratori o messi per dirimere le cause più complesse ${ }^{154}$.

153 Elze (cit. nota 105) pp. 169sg. Il testo della lettera in: Die Register Innocenz' III. 9. Pontifikatsjahr, 1206-1207, bearbeitet von Andrea Sommerlechner/Othmar Hageneder/Christoph Egger/Rainer Murauer/Herwig Weigl, Wien 2004 (Publikationen des historischen Instituts beim Österreichischen Kulturforum in Rom 1/9), p. 79 n. 43 : Per tuas nobis litteras intimasti, quod, cum aliqui Romane ecclesie subdiaconi prelationes in tua diocesi assecuntur, pro quibus tibi tenentur obedientiam exhibere (...) illi subdiaconatus privilegium allegantes ea se asserunt non teneri, ac si per huiusmodi subdiaconatus officium ab obedientia, qua tibi tenentur ratione obtenti beneficii sunt exempti. (...) Ad quod tibi breviter respondemus, quod, etsi decens sit, ut illis specialiter quantum convenit a te inter alios tibi subditos deferatur, quos benignitas apostolica collatione ipsius ordinis honoravit, per eum tamen et obedientia, quam alias tibi debent, minime absolventur.

154 Mi limito qui a richiamare i casi di Guglielmo Balbo, nel 1199 inviato alla curia papale come procuratore dell'arcivescovo Filippo da Lampugnano per difendere gli interessi della Chiesa ambrosiana nel corso dell'annosa questione relativa al monastero di Scozola (vedi sopra, nota 143 e testo corrispondente), e di Obizo de Castello, canonico di Novara, inviato alla curia papale per ottenere la conferma del conferimento di un beneficio nel capitolo della cattedrale (vedi sopra nota 133 e testo corrispondente). 
Ritengo, inoltre, che tra i motivi che rendevano ambita l'ordinazione suddiaconale ad opera del papa fosse la possibilità di ottenere ragguardevoli benefici, al fine di potersi dedicare con maggior agio agli studi: una più attenta analisi delle carriere dei chierici insigniti di questa carica, infatti, mi sembra suggerisca l'alto livello della loro preparazione culturale, un motivo che li rendeva esponenti ancor più qualificati della politica papale nelle diverse Chiese ${ }^{155}$. Essere ordinati suddiaconi dal pontefice, pur senza rimanere a servizio del vescovo di Roma, costituiva una notevole opportunità, giacché, con l'appoggio del papa o di importanti esponenti della curia romana diveniva possibile aspirare a ricche prebende in uno o più collegi di chierici, dove poi era in ogni caso garantita una certa libertà di azione, giacché i suddiaconi papali continuavano a dipendere dal vescovo di Roma. In tal modo i chierici desiderosi di intraprendere carriere di studio, un motivo che spesso coincideva con l'aspirazione a una brillante carriera ecclesiastica, potevano in forza della loro ordinazione papale ottenere benefici che consentissero loro di dedicarsi per un certo numero di anni allo studio a Parigi o a Bologna ${ }^{156}$.

È dunque auspicabile un censimento dei suddiaconi presenti nei diversi capitoli - di cattedrali o di chiese importanti, non solo nella regione padana per poter verificare, laddove la documentazione lo consenta, se essi erano anche suddiaconi della Chiesa romana ${ }^{157}$.

\section{Dai suddiaconi ai cappellani}

D'altra parte ai vantaggi loro concessi si accompagnava, come si è visto, l'obbligo di assumere delicati e spesso difficili incarichi per conto del pontefice, come potevano essere le legazioni, il recapito di importanti missive o l'esecuzione di ordini papali contrastati in sede locale ${ }^{158}$.

155 Indico appena i suddiaconi papali lombardi per i quali è stato possibile accertare il titolo di magister: Marescotto, Aicardo di Ivrea, Giovanni Buono da Fornovo, Pietro Diani, Sicardo di Cremona, Uberto da Pirovano.

156 Peter Classen: La curia romana e le scuole di Francia, in: Le istituzioni ecclesiastiche (cit. nota 55) pp. 432-436; ID.: Rom und Paris: Kurie und Universität im 12. und 13. Jahrhundert, in: ID.: Studium und Gesellschaft im Mittelalter, hg. von Johannes Fried, Stuttgart 1983 (MGH Schriften 29), pp. 127-169; Maleczek Verankerung (cit. nota 51) pp. 102-174.

157 ELZE (cit. nota 105) p. 157 nota 70: „Sichere Anhaltspunkte für die Identifizierung von Subd. und Kap. gibt es nicht. Die auswärtigen päpstl. Subd. haben wohl meistens nicht zur Kapelle gehört. Die Auswahl der nachstehend angeführten Subdiakone ist daher willkürlich, doch schien es im Rahmen dieser Arbeit unmöglich, sie alle (es sind über 100) zu berücksichtigen".

158 In tale prospettiva è illuminante il caso del suddiacono papale Alexius, i cui incarichi sono facilmente ricostruibili grazie all'epistolario da lui raccolto e conservato presso la 
Non solo. A partire dagli ultimi decenni del XII secolo, quando la presenza dei suddiaconi papali nei capitoli cominciò a essere consistente, essi divennero uno strumento importante nell'esercizio di quello che potremmo definire un controllo quotidiano dell'operato dei vescovi, soprattutto quando i presuli, spesso troppo coinvolti nelle vicende politiche delle città da cui provenivano $\mathrm{e}$ della cui Chiesa sovente erano anche a capo, faticavano a rispondere adeguatamente alle direttive papali ${ }^{159}$. Basti pensare ai numerosi casi in cui $\mathrm{i}$ vescovi della regione padana, già dallo scorcio del XII secolo, se da una parte dovettero far ricorso alla sede apostolica per ottenere il necessario appoggio nei confronti dei rispettivi comuni, dall'altro faticarono a rispondere alle pressanti direttive romane, già abbozzate nel canone 19 del III concilio lateranense ${ }^{160}$.

I suddiaconi papali si presentavano così come uno strumento assai duttile e al tempo stesso efficace per interventi di diversa natura, anche politica, ma soprattutto, quando si allentò la forte tensione che aveva segnato il periodo dello scontro tra Alessandro III e il Barbarossa, essi furono largamente impegnati in compiti di carattere disciplinare, volti a favorire l'introduzione in sede locale delle direttive romane - fossero queste di carattere politico, oppure semplicemente per garantire l'attuazione delle nomine di ecclesiastici graditi alla sede apostolica. La risposta di Innocenzo III, che già nel 1198 autorizzava l'arcivescovo Filippo da Lampugnano a ordinare ai gradi maggiori anche i suddiaconi della Chiesa romana, consente di collocare a quella data una svolta per la storia dei suddiaconi papali, alla quale sembra seguire un certo ridimensionamento, almeno per quanto riguarda la loro rappresentatività nei capitoli.

Una svolta succesiva di non facile decifrazione si ebbe con il pontificato di Innocenzo IV e con la decisa affermazione dei cappellani papali, il cui numero cominciò allora a lievitare ${ }^{161}$. In considerazione dei lunghi soggiorni dei cardinali

canonica parigina di S. Vittore: Papsturkunden in Frankreich N.F. 8 (cit. nota 5) pp. 62-64 con l'indicazione dei relativi documenti; vedi anche i casi ricordati sopra note $115-126$.

$159 \mathrm{Mi}$ è parso di poter mettere in luce questo motivo a proposito dei vescovo di Ivrea Giovanni, accusato presso la sede papale di aver dissipato i beni della sua Chiesa probabilmente dal potente preposito della cattedrale eporediese, il suddiacono papale Aicardo: vedi Alberzoni Città (cit. nota 65) pp. 232-239.

160 Ibid. pp. $27-37$.

161 Elze (cit. nota 105) pp. 170sg.: „Und wenn auch die Subdiakone in den Registern von Innozenz III., Honorius III. und Gregor IX. eine ähnliche Rolle spielen wie in den Urkunden des 12. Jhs., seit Innozenz IV. verschwinden sie fast ganz ... . Zu der gleichen Zeit erhöhte sich die Zahl der päpstlichen Kapelläne um ein Vielfaches dadurch, daß nun auch in weitem Umfange auswärtige Geistliche diesen Rang erhielten, die sicher niemals dem Papst als Kapellan gedient hatten. So ging die Funktion der auswärtigen Subdiakone auf die auswärtigen Kapelläne über ... . Warum aber die Subdiakone schließlich durch die Kapelläne ersetzt wurden von denen sie sich in die Stellung nach außen hin kaum unterschieden haben, ist schwer zu sagen". 
e della massiccia presenza di suddiaconi della Chiesa romana - con la totale affermazione dell'autorità giurisdizionale del papa sulla Chiesa intera saranno semplicemente definiti suddiaconi papali ${ }^{162}$ - nelle Chiese dell'Italia settentrionale il papato poteva dunque procedere a una drastica riduzione dell'invio di legati, ottenendo inoltre un più fattivo controllo sulle Chiese locali stesse ${ }^{163}$.

Si trattava di sperimentazioni, messe in atto dalla sede apostolica nel tentativo di rendere più organici e incisivi i suoi interventi nella regione padana, che indubbiamente diedero frutti non trascurabili. È possibile ipotizzare che, in considerazione dell'accresciuto numero dei suddiaconi e della loro provenienza dalle diverse regioni, non sempre il papa potesse avere di loro una conoscenza approfondita, al punto da poterli considerare strumenti del tutto affidabili; inoltre taluni suddiaconi papali, che pure erano stati accolti entro un capitolo, nel quale erano anche giunti a ricoprire importanti dignità, non si erano rivelati all'altezza della situazione e avevano fatto prevalere interessi personali o familiari, proprio quelli che la sede apostolica pensava di debellare ${ }^{164}$. Furono forse motivi come questi a favorire la progressiva affermazione dei cappellani papali. Quella dei suddiaconi della Chiesa romana può dunque essere considerata come una sperimentazione entro il vivace 'laboratorio' politico e diplomatico quale fu la curia papale per tutto il XII secolo, il secolo cruciale per l'affermazione del primato romano in Occidente.

\section{Considerazioni conclusive}

L'osservazione dei rapporti tra la sede apostolica e le Chiese padane soprattutto nel XII secolo consente di apprezzare l'importanza dell'opera del Kehr, che certo ha nell'Italia Pontificia la sua espressione più compiuta. Si tratta, infatti, di uno strumento fondamentale per le ricerche non solo sulle relazioni tra centro e periferia, ma anche per conoscere le modalità del governo delle singole Chiese. A questo proposito è doveroso rimarcare l'utilità dello spazio dedicato alla documentazione relativa ai legati papali, sia cardinali, sia di rango inferiore. Grazie alle ricerche di Stefan Weiß, ad esempio, disponiamo ora di un attendibile repertorio della documentazione prodotta dai legati, fossero essi

162 Ibid. p. 157: „Ferner mußte ein ,subdiaconus S.R.E.' als Vertreter der Römischen Kirche, ein ,capellanus domini pape' als Diener des Papstes erscheinen, und der Wechsel von ,subdiaconus S.R.E.' über ,subdiaconus domini pape' und ,capellanus domini pape' zu ,subdiaconus et capellanus domini pape' gehört in die Entwicklung, die von der Autorität der Römischen Kirche zur Herrschaft des Papstes im Abendland führt“.

163 Ambrosioni (cit. nota 2) pp. 435-442.

164 Anche a questo proposito rimando all'esemplare caso del suddiacono papale Aicardo di Ivrea, coinvolto in una complessa vicenda patrimoniale e politica, rivelatasi fallimentare per la Chiesa e il comune di Ivrea: Alberzoni Città (cit. nota 65) pp. 236-241 e 247. 
cardinali, o no. Sarebbe egualmente utile e auspicabile un aggiornato repertorio della documentazione cardinalizia, almeno fino a tutto il XII secolo, con particolare attenzione ai sigilli e alle caratteristiche formali degli atti.

Sarebbe parimenti auspicabile l'adeguata valorizzazione anche della documentazione relativa ad altre importanti figure al servizio del pontefici nei delicati compiti di governo, mi riferisco ai giudici delegati papali e, soprattutto, ai suddiaconi della Chiesa romana, come ho cercato di mettere in evidenza nel presente lavoro. Per queste categorie, ad esempio, le fonti pubblicate nei „Papsturkunden“ relativi ai regni di Francia e di Inghilterra, grazie anche alla più sofisticata metodologia adottata e alla valorizzazione delle raccolte epistolari conservatesi, consentono di valutare in modo più esauriente il significato delle missioni svolte anche da chierici di rango minore in risposta a direttive apostoliche, sia in questioni politiche di vasto respiro, sia nell'adempimento di incarichi più 'quotidiani', ma non meno significativi, quali il conferimento di benefici nei capitoli delle cattedrali o di importanti chiese, sia nel garantire l'esecuzione di disposizioni papali. A questo proposito indubbiamente la documentazione degli ultimi decenni del XII e dell'inizio del XIII secolo offre maggiori indicazioni, ma spesso si riferisce con estremo dettaglio a fatti avvenuti prima del $1198^{165}$.

Uno strumento di fondamentale importanza sarebbe in primo luogo la compilazione di un censimento il più possibile completo degli ecclesiastici attivi in sede locale - legati, cardinali, suddiaconi e giudici delegati - per incarico della sede apostolica: si tratta di un lavoro che potrà costituire la base per individuare e per valorizzare adeguatamente la documentazione utile, sia di provenienza papale, sia prodotta nelle diverse regioni. A questo proposito $\mathrm{mi}$ sembra di una certa utilità fornire un elenco degli ecclesiastici di origine lombarda, o che nella regione avevano ricoperto una importante dignità, creati cardinali prima del 1198. Si tratta di un primo contributo, sicuramente bisognoso di verifiche e precisazioni, su un problema che ancora non si può dire totalmente risolto ${ }^{166}$.

D'altra parte non bisogna dimenticare che nei cento anni che oramai ci separano dal primo volume dell'Italia Pontificia la documentazione nuovamente

165 A puro titolo esemplificativo, si veda la ricostruzione delle vicende che portarono alla fondazione della diocesi di Alessandria e alla nomina del primo vescovo nella persona del suddiacono papale Arduino, ben descritta nella documentazione di Innocenzo III (vedi sopra, nota 65) e l'assegnazione di un beneficio nel capitolo di S. Maria di Novara da Parte di Celestino III (vedi sopra, note 132sg.); l'importante ruolo svolto dai delegati nell' adempimento degli ordini papali è ben delineato da Harald MüLler: Entscheidung und Nachfrage. Die delegierten Richter als Verbindungsglieder zwischen Kurie und Region sowie als Gradmesser päpstlicher Autorität, in: JoHrendt/MüLler: Zentrum (cit. note 8) pp. 109-131.

166 Vedi la tabella in Appendice. 
edita, o edita in modo più accurato ${ }^{167}$, è cresciuta con un ritmo costante e, soprattutto negli ultimi decenni, ha assunto caratteri di apprezzabile scientifi$\operatorname{cità~}^{168}$. Non dimentichiamo poi anche i numerosi sussidi elettronici e le edizioni „in rete“, come il già ricordato Codice diplomatico della Lombardia ${ }^{169}$.

Inoltre la storiografia ha tratto molto vantaggio anche da una nuova valorizzazione del materiale già edito, che ovviamente può sempre fornire nuove risposte a domande „nuove“, vale a dire sostenute da nuovi orizzonti di ricerca. In alcuni casi, come si è visto, mi è stato possibile integrare notizie sugli interventi di papi, di cardinali e di suddiaconi proprio a partire dalla documentazione cosiddetta privata, in primo luogo i testimoniali, dove spesso sono riprese le diverse fasi di questioni agitate in tempi precedent $\mathrm{i}^{170}$. Le stesse osservazioni valgono anche per il materiale cronachistico, o diplomatistico, di cui pure sono apparse nuove importanti edizioni nelle classiche collane promosse dai MGH e dall'Istituto Storico italiano per il Medio Evo ${ }^{171}$.

Per tutte questi motivi rimane in ogni caso fondamentale, come già era ben presente nel metodo di lavoro del Kehr, il riferimento alla documentazione papale che risulta decisamente più precisa nella terminologia, soprattutto per quanto riguarda le istituzioni ecclesiastiche e l'indicazione delle qualifiche dei chierici. Senza peraltro dimenticare che talora anche la documentazione papale successiva (anche di molti anni) consente di conoscere nei dettagli lo

167 Basti qui solo un cenno alla meritoria opera dell'edizione viennese dei Registri di Innocenzo III, avviata dal prof. Othmar Hageneder, che è giunta alla pubblicazione del volume relativo al decimo anno di pontificato: Die Register Innocenz III. 10. Pontifikatsjahr, 1207/1208. Texte und Indices, a cura di Rainer Murauer/Andrea Sommerlechner/Othmar Hageneder/Christoph Egger/Reinhard Selinger/Herwig WeIgL, Wien 2007 (Publikationen des Historischen Instituts beim Österreichischen Kulturforum in Rom, II/110): grazie agli accurati indici e alle preziose note storiche, infatti, è ora possibile individuare agevolmente il richiamo a persone e documenti del periodo precedente; così pure merita di essere segnalato il Codice diplomatico della Chiesa bolognese. Documenti autentici e spuri (secoli IV-XII), a cura di Mario Fanti/ Lorenzo Paolini, Bologna 2004.

168 In proposito sono punto di riferimento i contributi raccolti in: Vom Nutzen des Edierens. Akten des internationalen Kongresses zum 150-jährigen Bestehen des Instituts für Österreichische Geschichtsforschung (Wien, 3.-5. Juni 2004), hg. von Brigitte Merta/Andrea Sommerlechner/Herwig Weigl, Wien/München 2005 (MIÖG Ergänzungsband 47).

169 Vedi sopra nota 41.

170 Valga per tutti la possibilità di individuare il nome della famiglia del cardinale Guglielmo da Pavia, vedi sopra, nota 42.

171 Maria Pia Alberzoni: Considerazioni su nuove proposte metodologiche nell'edizione delle fonti in ambito italiano, in: Vom Nutzen des Edierens (cit. nota 168) pp. 313328; lo stato della ricerca e delle edizioni di fonti e delineato in: Stato della ricerca e prospettive della medievistica tedesca, a cura di Michael Matheus/Massimo Miglio, Roma 2007 (Nuovi Studi storici 71). 
svolgimento di fatti relativi ai precedenti pontificati. Ma si tratta, ovviamente, di una casistica piuttosto circoscritta. 


\section{Appendice 1}

Cardinali lombardi creati tra 1110 e $1198^{*}$

1) Giovanni da Crema, CP di S. Crisogono 1116-1137

2) Gerardo da Bologna, CP di S. Croce in Gerusalemme 1123-1144, poi Lucio II $(1144 / 1145)$

3) Azzo, preposito della canonica di S. Antonino di Piacenza, CP di S. Anastasia $1134-1139$

4) Ribaldo, canonico di Piacenza, CD di S. Maria in Portico 1139, CP di S. Anastasia $1140-1156$

5) Goizone, CP di S. Cecilia 1140-1144

6) Guido da Somma, CP di S. Lorenzo in Damaso 1143; CV di Ostia $1149-1151$

7) Guarino da Bolona 1144

8) Ugo da Novara, CP di S. Lorenzo in Lucina 1144-1150

9) Guido da Crema, CD di S. Maria in Portico 1145, CP di S. Maria in Trastevere 1158-1164, dal 1164 antipapa con il nome di Pasquale III (1164-1168)

10) Oddo da Brescia, CD di S. Nicola in Carcere Tulliano 1152-1174

11) Ilebrando Crassus da Bologna, cardinale S.R.E. 1152; CD di S. Eustachio 1153, CP dei SS. XII Apostoli 1156-1178

12) Ardizzone da Rivoltella, CD di S. Teodoro 1157-1186

13) Guglielmo da Pavia (o de Marengo), CP di S. Pietro in Vincoli 1158-1176, CV di Porto $1176-1178$

14) Manfredo di Lavagna, CD di S. Giorgio in Velabro 1162, CP di S. Cecilia 1173, CV di Preneste 1176-1178

15) Galdino della Sala, CP di S. Sabina 1165-1167 poi arcivescovo di Milano

16) Ugo di Bologna, CD di S. Eustachio 1166-1177

17) Lombardo da Piacenza, CP di S. Ciriaco 1171, poi arcivescovo di Benevento

18) Pietro da Pavia, CP di S. Crisogono 1173, CV di Tuscolo 1179-1182

19) Raniero parvus da Pavia, CD di S. Giorgio in Velabro 1175, CP dei SS. Giovanni e Paolo 1182/1183

20) Uberto Crivelli, CP di S. Lorenzo in Damaso 1182-1185, poi arcivescovo di Milano (1185 maggio-novembre), quindi papa Urbano III 1185-1187

21) Adelardo, CP di S. Marcello 1185, dal 1188 vescovo di Verona

22) Pietro Diani, CD di S. Nicola in Carcere Tulliano 1185, CP di S. Cecilia $1188-1206$

23) Giovanni, già vescovo di Tuscania, CP di S. Clemente 1189, CV di Albano $1199-1210$

* Legenda: $\mathrm{CD}=$ cardinale diacono $\mathrm{CP}=$ cardinale prete; $\mathrm{CV}=$ cardinale vescovo 


\section{Appendice 2}

I cardinali lombardi sono qui collocati secondo scansioni cronologiche, per mettere in luce l'entità della loro presenza all'interno del collegio cardinalizio nel corso del XII secolo.

\begin{tabular}{|c|c|}
\hline $\begin{array}{l}1111- \\
1120\end{array}$ & Giovanni da Crema, 1116 CP di S. Crisogono \\
\hline \multirow{2}{*}{$\begin{array}{l}1121- \\
1130\end{array}$} & Giovanni da Crema, CP di S. Crisogono \\
\hline & Gerardo da Bologna, $1123 \mathrm{CP}$ di S. Croce in Gerusalemme \\
\hline \multirow{4}{*}{$\begin{array}{l}1131- \\
1140\end{array}$} & Giovanni da Crema, CP di S. Crisogono $(\dagger 1137)$ \\
\hline & Gerardo da Bologna, CP di S. Croce in Gerusalemme \\
\hline & Azzo, 1134 CP di S. Anastasia († 1139) \\
\hline & Ribaldo, 1139 CD di S. Maria in Portico \\
\hline \multirow{7}{*}{$\begin{array}{l}1141- \\
1150\end{array}$} & Gerardo da Bologna, CP di S. Croce in Gerusalemme $(\dagger 1144-1145)$ \\
\hline & Ribaldo, 1140 CP di S. Anastasia \\
\hline & Goizone, 1140 CP di S. Cecilia $(† 1144)$ \\
\hline & $\begin{array}{l}\text { Guido da Somma, 1143-1149 CP di S. Lorenzo in Damaso, } 1149 \text { CV di } \\
\text { Ostia }\end{array}$ \\
\hline & Guarino da Bologna (1144) \\
\hline & Ugo da Novara, 1144 CP di S. Lorenzo in Lucina († 1150) \\
\hline & Guido da Crema, 1145 CD di S. Maria in Portico \\
\hline \multirow{7}{*}{$\begin{array}{l}1151- \\
1160\end{array}$} & Ribaldo, CP di S. Anastasia $(\dagger 1156)$ \\
\hline & Guido da Somma, CV di Ostia († 1151) \\
\hline & Oddo da Brescia, 1152 CD di S. Nicola in Carcere Tulliano \\
\hline & $\begin{array}{l}\text { Ilebrando Crassus da Bologna, } 1153 \text { CD di S. Eustachio, } 1156 \text { CP dei SS. } \\
\text { XII Apostoli }\end{array}$ \\
\hline & Ardizzone da Rivoltella, 1157 CD di S. Teodoro \\
\hline & Guido da Crema, 1158 CP di S. Maria in Trastevere \\
\hline & Guglielmo da Pavia, 1158 CP di S. Pietro in Vincoli \\
\hline
\end{tabular}




\begin{tabular}{|c|c|}
\hline \multirow{7}{*}{$\begin{array}{l}1161- \\
1170\end{array}$} & Guido da Crema, CP di S. Maria in Trastevere \\
\hline & Oddo da Brescia, CD di S. Nicola in Carcere Tulliano \\
\hline & Ilebrando Crassus da Bologna, CP dei SS. XII Apostoli \\
\hline & Ardizzone da Rivoltella, CD di S. Teodoro \\
\hline & Guglielmo da Pavia, CP di S. Pietro in Vincoli \\
\hline & Manfredo di Lavagna, 1162 CD di S. Giorgio in Velabro \\
\hline & $\begin{array}{l}\text { Galdino della Sala, } 1165-1167 \text { CP di S. Sabina, poi arcivescovo di } \\
\text { Milano }\end{array}$ \\
\hline & Ugo di Bologna, 1166 CD di S. Eustachio \\
\hline \multirow{9}{*}{$\begin{array}{l}1171- \\
1180\end{array}$} & Oddo da Brescia, CD di S. Nicola in Carcere Tulliano $(\dagger 1174)$ \\
\hline & Ilebrando Crassus da Bologna, CP dei SS. XII Apostoli († 1178) \\
\hline & Ardizzone da Rivoltella, CD di S. Teodoro \\
\hline & $\begin{array}{l}\text { Guglielmo da Pavia, CP di S. Pietro in Vincoli, } 1176 \text { CV di Porto }(\dagger \\
\text { 1178) }\end{array}$ \\
\hline & Ugo di Bologna, CD di S. Eustachio $(\dagger 1177)$ \\
\hline & $\begin{array}{l}\text { Lombardo da Piacenza, } 1171 \text { CP di S. Ciriaco, poi arcivescovo di } \\
\text { Benevento }\end{array}$ \\
\hline & $\begin{array}{l}\text { Manfredo di Lavagna, } 1173 \text { CP di S. Cecilia, } 1176 \text { CV di Preneste }(\dagger \\
1178)\end{array}$ \\
\hline & Pietro da Pavia, 1173 CP di S. Crisogono, 1179 CV di Tuscolo \\
\hline & Raniero parvus da Pavia, 1175 CD di S. Giorgio in Velabro \\
\hline \multirow{7}{*}{$\begin{array}{l}1181- \\
1190\end{array}$} & Ardizzone da Rivoltella, CD di S. Teodoro $(\dagger 1186)$ \\
\hline & Pietro da Pavia, CV di Tuscolo $(† 1182)$ \\
\hline & Raniero parvus da Pavia, 1182 CP dei SS. Giovanni e Paolo ( $† 1183)$ \\
\hline & Uberto Crivelli, $1182-1185$ CP di S. Lorenzo in Damaso \\
\hline & Adelardo, 1185-1188 CP di S. Marcello, poi vescovo di Verona \\
\hline & $\begin{array}{l}\text { Pietro Diani, } 1185 \text { CD di S. Nicola in Carcere Tulliano, } 1188 \text { CP di S. } \\
\text { Cecilia }\end{array}$ \\
\hline & $\mathrm{i}, \mathrm{g}$ \\
\hline
\end{tabular}




\begin{tabular}{|l|l|}
\hline $\begin{array}{l}1191- \\
1200\end{array}$ & Pietro Diani, CP di S. Cecilia \\
\hline & Giovanni, CP di S. Clemente, 1199 CV di Albano \\
\hline
\end{tabular}

\section{Zusammenfassung}

Paul Kehr betont zuerst das starke Engagement des apostolischen Stuhls in der Lombardei: dieser bedient sich verschiedener Instrumente, um enge Verbindungen zwischen den Kirchen der Kirchenprovinz Mailand zu stiften: die Papstreisen in die Region, die zahlreichen lombardischen Kardinäle - viele davon waren im nördlichen Italien als päpstliche Legaten zugegen und hielten sich dort lange auf - sowie die päpstlichen Subdiakone. Die Aufgaben, die den Subdiakonen lombardischer Herkunft - deren Zahl in der zweiten Hälfte des 12. Jahrhunderts beachtlich zunahm - übertragen wurden, waren vielfältig. Darüber hinaus konnten sie mit päpstlicher Unterstützung einen Platz in den Kathedralkapiteln einnehmen; dort erhielten sie Pfründe, meist um für ihren Unterhalt während der Studien zu sorgen, und dort bildeten sie ein nützliches Kommunikationsmittel zwischen Zentrum und Peripherie, sowohl zur Abwicklung wichtiger Aufträge, als auch zur Erfüllung rechtlicher Aufgaben den Papst betreffend, dem gegenüber sie nur Rechenschaft ihrer Handlungen ablegen mussten. Am Anfang seines Pontifikats gewährte Innozenz III. dem Erzbischof von Mailand das Recht, die Subdiakone der römischen Kirche, die im Mailänder Klerus zugegen waren, in die großen Orden zu versetzten. Damit leitete er eine erste "Ablösung" zwischen ihnen und apostolischem Stuhl ein. Unter Innozenz IV. wurde die Regel, die erstmals von päpstlichen Subdiakonen ausgeführt worden war, von den päpstlichen Kaplänen angenommen. 
Bereitgestellt von | De Gruyter / TCS

Angemeldet | 217.89.40.26

Heruntergeladen am | 21.12.12 10:48 